\title{
Nanolubricant additives: A review
}

\author{
Jun ZHAO ${ }^{1,2,3}$, Yiyao HUANG ${ }^{1}$, Yongyong $\mathbf{H E}^{2, *}$, Yijun $\mathbf{S H I}^{3}$ \\ ${ }^{1}$ College of Mechanical and Electrical Engineering, Beijing University of Chemical Technology, Beijing 100029, China \\ ${ }^{2}$ State Key Laboratory of Tribology, Tsinghua University, Beijing 100084, China \\ ${ }^{3}$ Division of Machine Elements, Luleå University of Technology, Lulea 97187, Sweden
}

Received: 15 July 2020 / Accepted: 03 September 2020

(C) The author(s) 2020 .

\begin{abstract}
Using nanoadditives in lubricants is one of the most effective ways to control friction and wear, which is of great significance for energy conservation, emission reduction, and environmental protection. With the scientific and technological development, great advances have been made in nanolubricant additives in the scientific research and industrial applications. This review summarizes the categories of nanolubricant additives and illustrates the tribological properties of these additives. Based on the component elements of nanomaterials, nanolubricant additives can be divided into three types: nanometal-based, nanocarbonbased, and nanocomposite-based additives. The dispersion stabilities of additives in lubricants are also discussed in the review systematically. Various affecting factors and effective dispersion methods have been investigated in detail. Moreover, the review summarizes the lubrication mechanisms of nanolubricant additives including tribofilm formation, micro-bearing effect, self-repair performance, and synergistic effect. In addition, the challenges and prospects of nanolubricant additives are proposed, which guides the design and synthesis of novel additives with significant lubrication and antiwear properties in the future.
\end{abstract}

Keywords: nanolubricant additive; dispersion stability; tribological properties; lubrication mechanism

\section{Introduction}

Energy loss is an unneglected problem especially in the energy-shortage world, for instance, in a typical passenger car, $79 \%$ of fuel accounts for the energy loss, as shown in Fig. 1 [1]. Friction and wear are the main causes of energy loss and mechanical failure [2,3]. Approximately $1 / 3$ of the world's primary energy originates from friction consumption, and nearly $1 / 2$ of the power of transportation equipment is consumed in friction [4]. Especially, about $4 / 5$ of mechanical failure mainly results from worn-out parts. In addition, friction also causes serious problems with surface corrosion and environmental pollution. Therefore, reducing friction and wear plays an important role in prolonging mechanical equipment service life and in saving energy and emission reduction. Lubrication is one of the most effective ways to control friction and wear, which is of great significance for energy conservation, emission reduction, and environmental protection [5].

Various methods have been adopted to minimize

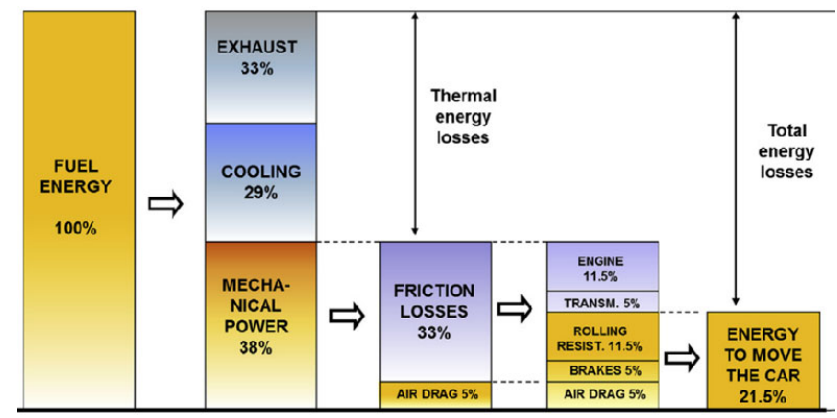

Fig. 1 Breakdown of passenger car energy consumption. Reproduced with permission from Ref. [1], C Elsevier, 2019.

* Corresponding author: Yongyong HE, E-mail: heyy@mail.tsinghua.edu.cn 
friction and wear to satisfy the requirements of energysaving. For instance, the optimization of the groove texture profile can further enhance the load-carrying capacity of oil film under the conditions of hydrodynamic lubrication [6]. Besides, lubricants which mainly include solid lubricants and liquid lubricants are widely used for lubrication. There are many advanced solid lubricants such as molybdenum disulfide $\left(\mathrm{MoS}_{2}\right)$ film [7], diamond-like coating [8], entangled carbon nanotube (CNT) film [9], and polymer material $[10,11]$. However, their tribological properties are directly influenced by the friction environment, and they are prone to being a wear-out failure after serving for a long time. Liquid lubricants can form a hydrodynamic or elastohydrodynamic lubrication film on friction interfaces during sliding friction, therefore widely used in the mechanical industry. Apart from lubricating oils, ionic liquids can sometimes be used as liquid lubricants [12]. When mechanical equipment is under start-up and shutdown stages and/or under extreme friction conditions, liquid lubricants cannot form a stable lubricating film between the friction pairs. Under such circumstances, boundary lubrication and mixed lubrication states occur, and result in severe friction and wear. Using lubricant additives is one of the most effective ways to reduce friction and wear under boundary lubrication. Traditional lubricant additives such as organic phosphates, organic sulfides, and organic metallic compounds, have good dispersing stabilities and tribological properties, but they all have different degrees of problems, such as toxicity, releasing sulfated ash, phosphorous and sulfur (SAPS, which would cause air pollution such as acid rain and haze weather [13]) and chemical corrosion. SAPS Although other additives such as ionic liquids have outstanding tribological performance and are environmental-friendly, they are high in cost, which restricts the application in industry [14, 15].

Nanomaterials because of atomic sizes and surface effects, display unique physical and chemical properties and have been widely investigated in the field of tribology. Nanomaterials using as lubricant additives can greatly improve the tribological properties of lubricating oil and have outstanding effects on reducing energy consumption and environmental protection [16]. Therefore, this review focuses on the development of nanolubricant additives, mainly including nanometal-based additives, nanocarbonbased additives, and nanocomposite-based additives. Their tribological properties are firstly systematically discussed. The dispersion stabilities of the nano additives are then described in detail. Furthermore, the review summarizes the lubrication mechanisms of nanolubricant additives including tribofilm formation, micro-bearing effect, self-repair performance, and synergistic effect. Finally, the challenges and prospects of nanolubricant additives are proposed.

\section{Nanolubricant additives}

With the development of nanotechnology, nanomaterials have become one of the most attractive fields in physics, chemistry, and materials science. Nanomaterials as lubricant additives because of their small sizes are easy to enter friction contact areas and can form a protection tribofilm, thereby preventing the surface of friction pairs from being worn. In addition, nanomaterials have high surface activity, which can improve the film-forming stability of protection tribofilm by physical and/or chemical adsorption effects. There are three basic types of nanolubricant additives: nanometal-based additives, nanocarbon-based additives, and nanocompositebased additives, as shown in Table 1.

\subsection{Nanometal-based lubricant additives}

The nanometal-based lubricant additives mainly include pure metals, metal oxides, metal sulfides, metal hydroxides, and metal salts. In the 1980s-1990s, Hisakado et al. [17] found that $\mathrm{Cu}$ nanoparticles as lubricant additives displayed excellent tribological properties in base oils for the first time. Then, $\mathrm{Cu}$ nanoparticles with good dispersed performance in lubricant were prepared by surface chemical modification $[18,19]$, as shown in Figs. 2(a) and 2(b). They also revealed the outstanding antifriction properties of modified $\mathrm{Cu}$ nanoparticles at a concentration of 0.3 wt $\%$ under different friction conditions, as shown in Figs. 2(c) and 2(d). Other nanometal materials with low melting points and weak shear forces such as Ag and In-Sn alloy nanoparticles have also been studied as nanolubricant additives [20, 21]. 
Table 1 Types of nanolubricant additives.

\begin{tabular}{|c|c|c|}
\hline \multicolumn{2}{|c|}{ Types of nanolubricant additives } & Examples \\
\hline \multirow{5}{*}{$\begin{array}{l}\text { Nanometal-based } \\
\text { lubricant additives }\end{array}$} & Pure metal & $\mathrm{Cu}[22,23], \operatorname{Ag}[21,24], \mathrm{Fe}[25,26], \mathrm{Pd}[27,28], \mathrm{Ni}[29]$ \\
\hline & Metal oxide & $\mathrm{CuO}[30-32], \mathrm{ZnO}[33,34], \mathrm{Al}_{2} \mathrm{O}_{3}[35], \mathrm{TiO}_{2}[36-38], \mathrm{ZrO}_{2}[39]$ \\
\hline & Metal sulfide & $\mathrm{WS}_{2}[40-42], \mathrm{MoS}_{2}[43-46], \mathrm{CuS}[47], \mathrm{ZnS}[48]$ \\
\hline & Metal hydroxide & $\mathrm{La}(\mathrm{OH})_{3}[49]$, LDHs $[50-51]$ \\
\hline & Metal salt & $\begin{array}{l}\mathrm{CaCO}_{3}[52], \mathrm{LaF}_{3}[53-55], \\
\mathrm{ZrP}[56], \text { Calcium Borate }[57,58], \text { Zinc Phosphate [59] }\end{array}$ \\
\hline \multirow{2}{*}{$\begin{array}{l}\text { Nanocarbon-based } \\
\text { lubricant additives }\end{array}$} & Pure carbon & $\begin{array}{l}\text { Nano Diamond }[60,61] \text {, Fullerenes [62], } \\
\text { Carbon Nanotubes }[63,64] \text {, Graphene [65-67] }\end{array}$ \\
\hline & Polymer & PTFE $[68,69]$, PSS [70], PVP [71] \\
\hline \multicolumn{2}{|c|}{$\begin{array}{l}\text { Nanocomposite-based } \\
\text { lubricant additives }\end{array}$} & $\begin{array}{l}\mathrm{Cu} @ \mathrm{SiO}_{2}[72], \mathrm{Al}_{2} \mathrm{O}_{3} @ \mathrm{TiO}_{2}[73], \mathrm{Cu} @ \mathrm{MoS}_{2}[74], \mathrm{G} @ \mathrm{MoS}_{2}[75], \\
\alpha-\mathrm{Fe}_{2} \mathrm{O}_{3} @ \mathrm{GO}[76], \mathrm{FeS}_{2} @ \mathrm{G}[77], \mathrm{Ag} @ \mathrm{G}[78,79], \mathrm{Cu} @ \mathrm{GO}[80], \\
\mathrm{Mn}_{3} \mathrm{O}_{4} @ \mathrm{G}[81], \mathrm{La}_{2} \mathrm{O}_{3} @ \mathrm{PI}[82], \\
\text { Alumina@MWCNT [83] }\end{array}$ \\
\hline
\end{tabular}
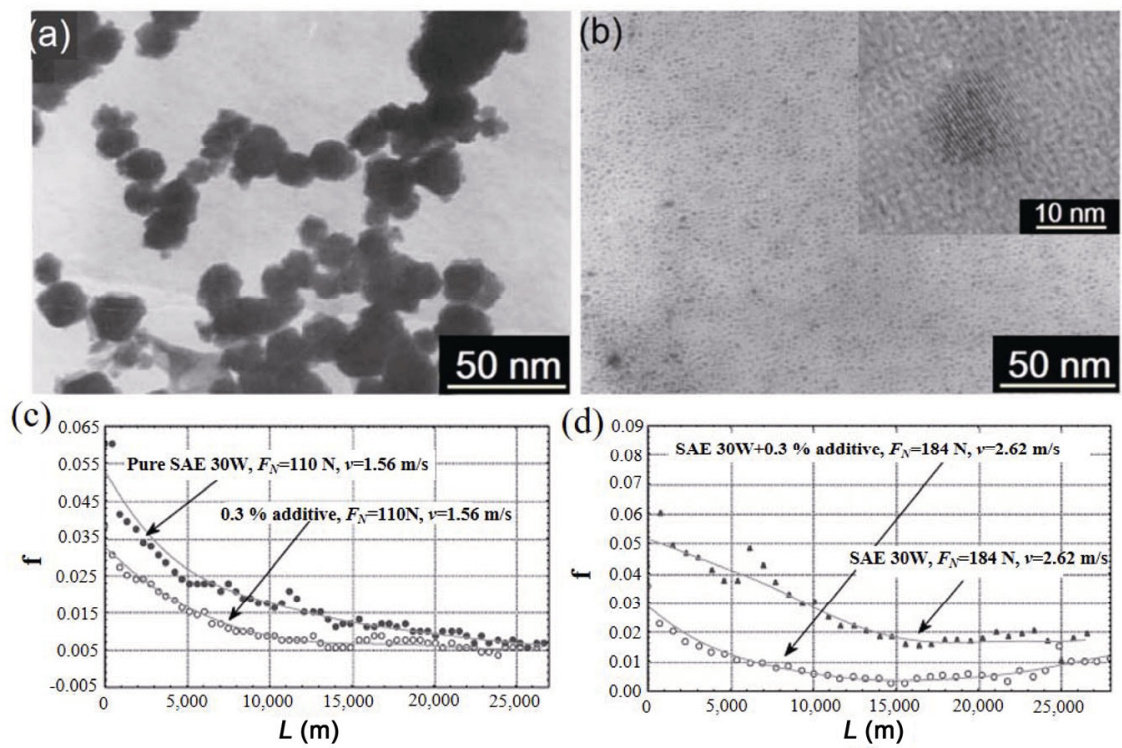

Fig. 2 Transmission electron microscope (TEM) images of (a) pure $\mathrm{Cu}$ nanoparticles and (b) $\mathrm{Cu}$ nanoparticles modified by chemical method. Reproduced with permission from Ref. [18], C) Elsevier, 1999. (c, d) The tribological properties of the nanoparticle as lubricant additives. Reproduced with permission from Ref. [19], (C) Elsevier, 2002.

Current researches have also confirmed the improved tribological properties with the addition of metallic nanoparticles such as Fe, Pd, Ni, etc. [25-29]. Through comparative studies, it is found that metal oxides such as $\mathrm{ZnO}[33,34], \mathrm{TiO}_{2}[36-38]$, and $\mathrm{ZrO}_{2}[39]$ have good lubrication properties, and the properties of nanometal oxides are closely related to particle size, hardness, and concentration. Wu et al. [84] indicated that $\mathrm{CuO}$ nanosheets apparently enhanced the antiwear performance of self-lubricating carbon fibers reinforced polytetrafluoroethylene (PTFE) as additives. Moreover, the research also found that $\mathrm{CuO}$ nanosheets exhibited superior antiwear properties to commercial $\mathrm{CuO}$ nanogranules. In addition, metal sulfides as lubricant additives have attracted much attention in the lubrication field. For example, $\mathrm{MoS}_{2}$ and tungsten disulfide $\left(\mathrm{WS}_{2}\right)$ can chemically interact with friction pairs and produce a stable adsorption film on rubbing surfaces, so that the tribological properties of lubricants can be effectively promoted under some extreme friction conditions [85]. Recently, $\mathrm{Yi}$ and Zhang [86] found that the tribological properties of $\mathrm{MoS}_{2}$ with lamellar morphology were much better than that of petal structure, indicating that $\mathrm{MoS}_{2}$ with lamellar structure had high chemical activity 
and was easier to display interlayer sliding effect. Moreover, $\mathrm{Hu}$ et al. [87] confirmed that spherical $\mathrm{MoS}_{2}$ nanoparticles had a superior antioxidant effect to $\mathrm{MoS}_{2}$ nanoparticles with layered structure, which further enhanced the lubrication stability. Chen et al. [88] revealed that ultrathin $\mathrm{MoS}_{2}$ nanosheets had much better extreme pressure characteristics than other metal sulfides because the ultrathin nanosheets were easier to enter the friction contact areas.

Moreover, metal hydroxides have also been proved to show outstanding lubrication performance, and among them, layered double hydroxides (LDHs) are the most representative. Owing to the laminated structure, small particle size, and high chemical activity, LDHs powders exhibit excellent friction and wear reduction properties especially under boundary lubrication conditions [50,51]. Apart from LDHs, $\mathrm{La}(\mathrm{OH})_{3}$ nanoparticles, another kind of metal hydroxide, have also been proved to be effective lubricant additives. Zhao et al. [49] synthesized $\mathrm{La}(\mathrm{OH})_{3}$ nanoparticles with granular shapes by sol-gel method and confirmed the enhanced friction-reduction and wear-resistance properties of base oil with the addition of $\mathrm{La}(\mathrm{OH})_{3}$ nanoparticles. Metal salts also have the potential for lubricant additives. $\mathrm{CaCO}_{3}$ nanoparticles were investigated as lubricant additives in the early 2000s. And the researches demonstrate that $\mathrm{CaCO}_{3}$ nanoparticles can facilitate obvious lubricating effect via the formation of tribofilm [52]. In addition, He et al. [56] confirmed the excellent antifriction performance of $\alpha$-Zirconium phosphate $(\mathrm{ZrP})$ nanoplatelets as lubricant additives. The results revealed that the friction coefficient was reduced by $65 \%$ and $91 \%$ in comparison with mineral oil and water respectively. The research attributed the outstanding frictionreduction properties to viscosity modification and intermolecular interaction. Comparative studies on the tribological properties have also been conducted on calcium borate [57,58], zinc phosphate [59] and $\mathrm{LaF}_{3}$ [53-55].

\subsection{Nanocarbon-based lubricant additives}

Compared with metal sulfide additives, carbon nanomaterials with good chemical stability and excellent mechanical properties offer excellent tribological properties together with environment-friendly performances for a sustainable future. Nanocarbonbased lubricant additives contain pure carbon and polymer, based on the chemical elements. Furthermore, according to various dimensions, pure carbon lubricant additives mainly include carbon quantum dot (CQD) (0D), nanodiamond (0D), fullerene C60 (0D), carbon nanotubes (1D), graphene (2D) and graphite (3D) [89]. Tu et al. [90] revealed that CQD enhanced the tribological properties of polyethylene glycol. Kim et al. [91] found that diamond nanoparticles can effectively promote the lubrication properties of base oil. Joly-Pottuz et al. [92] studied the tribological properties of nanodiamond compared with fullerene as lubricant additives. Diamond nanoparticles are prone to scratching rubbing surfaces during the sliding process. For comparison, fullerene because of shear deformation or even peeling into lamellar has better wear resistance. Liu et al. [93] concluded that the surface-modified carbon nanotubes can disperse well in the base oil, and it can form a "molecular brush" arrangement on rubbing surfaces and display a micro bearing-rolling lubrication effect. Zhang et al. [94] found that CNT walls were easily opened under high load and peeled off into graphene-like lamellar layers, so that good tribological property could be achieved through an interlayersliding effect. Graphene was first used in the research of nanolubricant additives for the first time in 2011 by Berman et al. [95]. After that, the investigation and application of graphene lubricant additives have been rapidly developed in recent years. Apart from pure carbon, polymer nanoparticles are also investigated as lubricant additives [96]. Kumar et al. [69] synthesized lithium greases with PTFE nanoparticles as additives and revealed the enhanced friction reduction and wear resistance properties with the addition of PTFE nanoparticles. Moreover, the study implied that size and shape were two factors that affect the lubricating performance. The tribological properties of poly (sodium 4-styrenesulphonate) (PSS) and polyvinylpyrrolidone (PVP) were investigated by Wang et al. [70] and Tu et al. [71]. The research confirms that the polymer nanoparticles can improve the antifriction and wear resistance of base lubricants effectively. 
Graphene, a typical 2D nanomaterial, displays green lubricating and self-lubricating properties. Especially, superlubricity and ultrahigh wear resistance can be achieved by graphene [97-100]. The state of graphene layers during the friction process is illustrated in Fig. 3(a). Compared with singlelayer graphene, multilayer graphene exhibits a much lower friction coefficient and much higher stability, as shown in Fig. 3(b). Moreover, graphene shows more potential for application in lubrication than other lubricant additives. Mechanical exfoliation is regarded as an effective method to prepare graphene with fewer layers. Berman et al. [95] revealed that small amounts of few-layer graphene can significantly improve the tribological performance. The results indicated that the friction coefficient and wear of graphene-containing ethanol solution reduced by a factor of 6 and almost 4 orders of magnitude respectively. However, the quality of the mechanicalexfoliation product is not guaranteed because the related operation is difficult to control. In addition, the cost of mechanical exfoliation is high and the efficiency is very low. Thus, other methods to prepare graphene have been developed. Eswaraiah et al. [101] exfoliated ultrathin graphene from graphite oxide with the assistance of focused solar radiation and investigated the tribological properties of graphene as additives. The results exhibited that the friction-reduction, antiwear, and extreme pressure properties were improved by $80 \%, 33 \%, 40 \%$ respectively. Mungse et al. [102] synthesized graphene from graphene oxide via a chemical reducing agent and indicated that graphene significantly enhanced the tribological properties. Schlüter et al. [103] examined the tribological performance of thermally reduced graphite oxide and confirmed its excellent properties on friction reduction and wear resistance. The reduction of graphite oxide has advantages on operation and cost, but the reduction procedure will lead to structural defects on graphene [104]. During thermal reduction, the release of gases will form holes and wrinkles on the graphene structure, which affects the lubricating performance. With the assistance of some chemical agents, such as $\mathrm{H}_{2} \mathrm{SO}_{4}$ and $\mathrm{KOH}$, Zhao et al. [105] have found that the structural defects of graphene during thermal reduction can be inhibited, which shows great
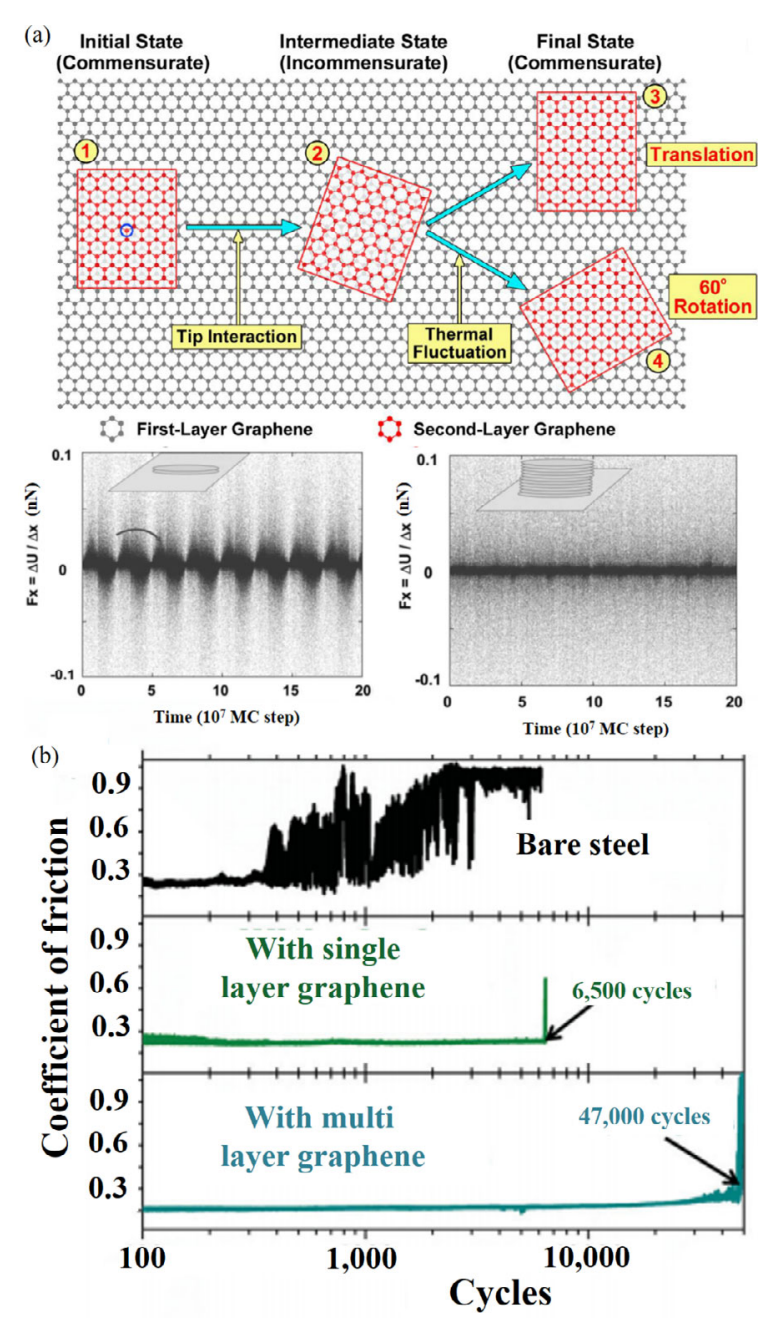

Fig. 3 (a) Superlubricity of graphene when graphene nanosheets slide on graphene surface by commensurateincommensurate state. Reproduced with permission from Ref. [97], (C) Royal Society of Chemistry, 2012; Ref. [100], (C) American Chemical Society, 2013. (b) The friction coefficient of graphene with ultra-high wear resistance. Reproduced with permission from Ref. [98], (C) Wiley, 2014.

meanings to obtain graphene with excellent antifriction and antiwear properties.

\subsection{Nanocomposite-based lubricant additives}

Compared with metal-based and carbon-based lubricant additives, nanocomposite-based additives have outstanding lubricating properties because the additives can form a compositive tribofilm on friction interfaces and have a synergistic lubricating effect. Zhang et al. [72] prepared $\mathrm{Cu} @ \mathrm{SiO}_{2}$ nanocomposites and the results exhibited a considerable improvement of tribological properties. Luo et al. 
[73] investigated the lubricating effect of $\mathrm{Al}_{2} \mathrm{O}_{3} @ \mathrm{TiO}_{2}$ nanocomposites as lubricant additives and confirmed the superior tribological properties of nanocomposites compared with pure $\mathrm{Al}_{2} \mathrm{O}_{3}$ or $\mathrm{TiO}_{2}$ nanoparticles. Moreover, a nanotube is a typical matrix of $1 \mathrm{D}$ nanocomposites. Li et al. [106] synthesized PVA@CNTs nanocomposites and found that both load-carrying capacity and anti-wear properties were improved with the addition of nanocomposites. Yu et al. [107] prepared room temperature ionic liquid (RTIL)@multiwalled carbon nanotubes (MWCNTs) composite and revealed good friction-reduction and antiwear properties. Comparative tribological tests are also conducted on 2D nanocomposites. 2D nanocomposites are composites with a layered structure, such as $\mathrm{MoS}_{2}$-based and graphene-based nanocomposites, and they are regarded as a promising material for lubricant additives in the future. Jia et al. [74] prepared $\mathrm{Cu} @ \mathrm{MoS}_{2}$ nanocomposites and investigated their tribological properties as lubricant additives. The experiments revealed that the optimal concentration of nanocomposites is $0.5 \mathrm{wt} \%$, and the average friction coefficient and wear scar width were reduced by $37.8 \%$ and $28.5 \%$ compared with other additives in pure sunflower oils, respectively. Furthermore, significant antifriction and antiwear effects are also achieved by dispersing graphene-based nanocomposites into base lubricants. Song et al. [75] synthesized $\mathrm{MoS}_{2} @$ graphene $\left(\mathrm{MoS}_{2} @ \mathrm{G}\right)$ composites and investigated their tribological performance. The results revealed that $\mathrm{MoS}_{2} @ \mathrm{G}$ nanocomposites can improve antifriction and antiwear properties. Song et al. [76] examined the lubricating performance of $\alpha-\mathrm{Fe}_{2} \mathrm{O}_{3} @ \mathrm{GO}$ composites and the results confirmed the tribological properties of this nanocomposite are better than both $\mathrm{Fe}_{2} \mathrm{O}_{3}$ nanoparticles and graphene nanosheets. The friction coefficient and wear scar diameter of friction pairs can be reduced by $67 \%$ and $70 \%$, respectively. Other graphene-based nanocomposites, such as $\mathrm{FeS}_{2} @ \mathrm{G}, \mathrm{Ag} @ \mathrm{G}$ and $\mathrm{Cu} @ \mathrm{GO}$, exhibit good antifriction and antiwear performance as well [77-80]. Generally, nanocomposites are mainly prepared by hydrothermal method. It is easy to control the shape and distribution density of nanoparticles on nanocomposites. Especially, Zhao et al. [81] prepared $\mathrm{Mn}_{3} \mathrm{O}_{4} @ \mathrm{G}$ nanocomposites via in situ green methods and investigated their tribological properties as shown in Fig. 4. The results showed that the friction coefficient and wear depth were respectively reduced by $75 \%$ and $97 \%$ in comparison with base oil at a very low concentration (0.075 $\mathrm{wt} \%)$.

Nanolubricant additives have prominent antifriction and wear-reduction properties, and they are regarded as the alternatives of traditional lubricant additives. Although metal sulfide nanomaterials such as $\mathrm{MoS}_{2}$ and $\mathrm{WS}_{2}$ display significant antifriction and antiwear properties among all these categories, the high content of sulfur results in severe corrosion of friction pairs and would be discarded due to environmental concern. Carbon-based nanomaterials
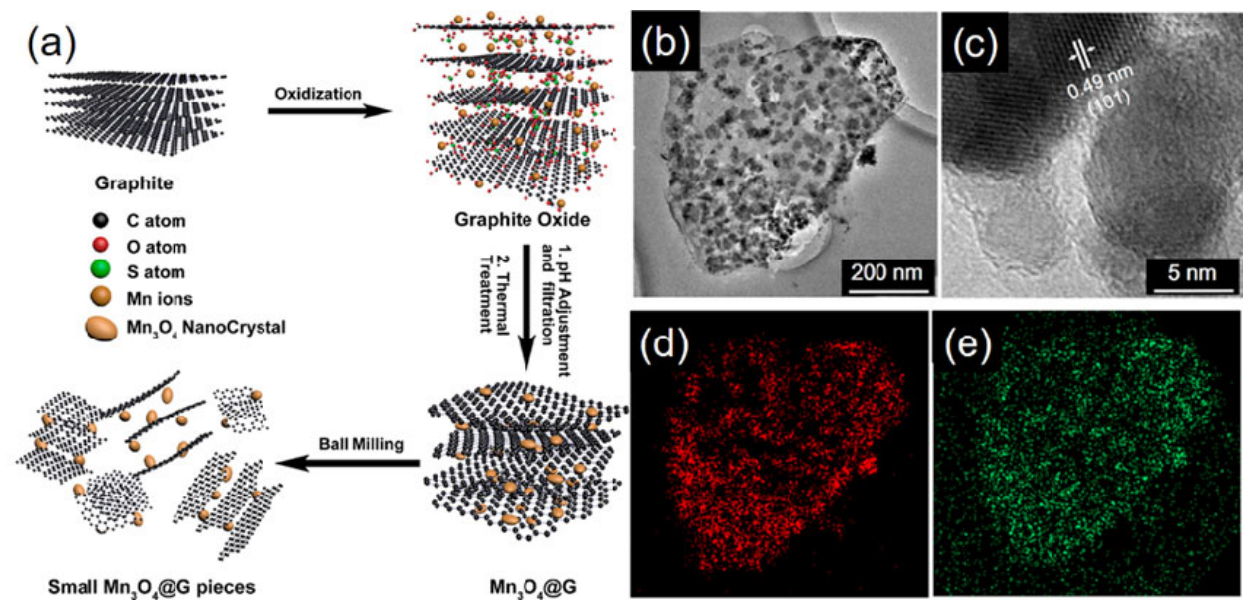

Fig. 4 (a) Synthesis schematic of $\mathrm{Mn}_{3} \mathrm{O}_{4} @ \mathrm{G}$ nanocomposites by an in situ green method, (b, c) TEM images of the nanocomposites, element mapping of (d) Mn and (e) O. Reproduced with permission from Ref. [81], C) American Chemical Society, 2019. 
offer both good tribological properties and environment-friendly performance for a sustainable future. Especially, graphene and graphene-based nanocomposites exhibit outstanding friction-reduction and wear-resistance properties and are also regarded as potential candidates for green and effective lubricant additives.

\section{Dispersion stability of nanolubricant additives}

Nanoparticles have high values of specific surface area, which leads to the increase of intermolecular forces, thereby exacerbating the aggregation of nanoparticles. Many research efforts have been directed towards producing stable nanolubricant additives, but even after several decades of research, the full potential of employing nanoparticles as lubricant additives has been severely limited because of the poor interfacial interaction between the additives and lubricants. Hence, it is necessary and instructive to analyze the factors affecting the dispersion stability and to explore the methods for enhancing the dispersion stability of nanoadditives.

\subsection{Affecting factors}

The natural characteristics of nanoparticles such as size, shape, and concentration in lubricants have great impacts on the dispersion stability. As known, nanoparticles with large specific surface areas and high surface activities are prone to forming intimate contact with each other, resulting in the aggregation of nanoparticles and weakening the dispersion stability. According to the Stokes law [108], $v=\frac{2 r^{2} g\left(\rho_{1}-\rho_{2}\right)}{9 \eta}(v$ represents the sedimentation velocity, $r$ represents radius of nanoparticles, g means gravitational acceleration, $\rho_{1}$ means density of nanoparticles, $\rho_{2}$ represents the density of the base fluid, and $\eta$ means viscosity of base fluid), is established to illustrate the affecting factors of sedimentation velocity. According to the Stokes law, the sedimentation velocity of nanoparticles is proportional to the square of the radius. Thus, the decrease of radius results in slow sedimentation velocity and enhanced dispersion stability. Choi et al. [109] confirmed that smaller Ag nanoparticles $(7 \mathrm{~nm})$ showed better dispersion stability than larger ones $(50 \mathrm{~nm})$. However, with the decrease in particle size, the surface energy of nanoparticles increases, and the aggregation intensifies. Therefore, using small nanoparticles and preventing aggregation should be taken into consideration simultaneously. In addition, the effect of shape on dispersion stability is related to the aspect ratio (length/diameter) of nanoparticles. Nanoparticles with high aspect ratio are more likely to agglomerate, which means spherical-shaped nanoparticles exhibit better dispersion stability than those with rod and tube-shaped ones [110]. Xing et al. [111] confirmed that fullerene C60 nanoparticles exhibited better dispersion stability than CNTs, which was attributed to the low aspect ratio of C60. Furthermore, the concentration of nanoparticles is another influential factor. High concentration makes nanoparticles closer to each other and increases the Van Der Waals attraction forces, so nanoparticles are easy to agglomerate at high concentrations. Kotia et al. [112] conducted experiments on dispersion stability of $\mathrm{Al}_{2} \mathrm{O}_{3}$ nanoparticles in gear oil at various concentrations ( $0.5 \mathrm{vol} \%, 1 \mathrm{vol} \%, 1.5 \mathrm{vol} \%, 2 \mathrm{vol} \%)$ and discovered that the suspension with the lowest concentration (0.5 vol\%) was the most stable over time. The characteristic of base lubricants, such as $\mathrm{pH}$ value also plays an essential role in the dispersion stability of the suspension. Recent researches have confirmed that an optimal $\mathrm{pH}$ value can prevent the aggregation of nanoparticles, thereby enhancing the dispersion stability. For instance, Zhu et al. [113] revealed that when the $\mathrm{pH}$ value was 9-9.5, $\mathrm{CaCO}_{3}$ nanoparticles exhibited the best stability in distilled water. As known, when the $\mathrm{pH}$ value is near isoelectric point (IEP) of nanoparticles, the agglomeration is intensified, thereby leading to poor dispersion stability. The research carried out by Chang et al. [36] confirmed that the optimal $\mathrm{pH}$ value of $\mathrm{TiO}_{2}$ nanofluid $(\mathrm{pH} 7)$ was departed from IEP ( $\mathrm{pH} 4)$.

\subsection{Methods to improve dispersion stability}

As known, the incorporation of solid nanoparticles into a liquid lubricant always results in difficulties uniformly disperse. There is a sizable volume of 
literature reported on the dispersion techniques such as physical methods, chemical methods, and self-dispersed methods. These dispersion methods are introduced here, and typical results on the dispersion in lubricants by these methods are demonstrated in Table 2.

\subsubsection{Physical methods}

There are many physical suspension processes such as mechanical stirring, ultrasonication, ball milling, and high-pressure homogenization. Molseh et al. [114] found that the dispersion stability of three different nanoparticles $\left(\mathrm{MoS}_{2}, \mathrm{WS}_{2}\right.$, hexagonal boron nitride (h-BN)) in CIMFLO 20 with ultrasonic treatment was better than that with mechanical shaking and stirring. The ultrasonic time is an essential factor that should be taken into consideration when preparing a stable suspension with the assistance of ultrasonication. Nanolubricant additives exhibit the best dispersion stability only after ultrasonication for an optimum time. Kumar et al. [68] compared the stability of PTFE particles in base lubricant with various ultrasonic time (30, 40, 60, and $90 \mathrm{~min})$. The results revealed that the optimal ultrasonic time was 60 min, and the suspension remained stable for 15 days shown in Fig. 5(a). Similar research is conducted by Sharif et al. [115]. They found that ultrasonication has a significant effect on reducing particle size, thereby enhancing the dispersion stability of $\mathrm{Al}_{2} \mathrm{O}_{3}$ aqueous fluids, as shown in Fig. 5(b). In addition, ball milling and high-pressure homogenization are also used in the preparation of lubricants. Ball milling is more efficient in breaking up the aggregated particles than ultrasonication. Ettefaghi et al. [116] found that copper oxide nanoparticles in SAE 20W50 with planetary ball mill method had less precipitation after $720 \mathrm{~h}$ than that with ultrasonic treatment.

Table 2 The dispersion stability of various nanolubricants.

\begin{tabular}{|c|c|c|c|c|c|}
\hline Dispersion & Additives & Lubricants & Dispersion Processes & Stabilities & References \\
\hline \multirow{4}{*}{$\begin{array}{l}\text { Physical } \\
\text { methods }\end{array}$} & $\begin{array}{l}\text { PTFE/ } \\
\text { MoS } 2 \text { Nanolayer } \\
\text { coated carbon spheres } \\
\left(\mathrm{CS}-\mathrm{MoS}_{2}\right) / \\
\mathrm{MoS}_{2}, \mathrm{WS}_{2}\end{array}$ & $\begin{array}{l}150 \mathrm{~N} / \\
5 \mathrm{~W} 30 / \\
\mathrm{PAG}\end{array}$ & ultrasonication & $\begin{array}{l}\text { For } 15 \text { days/ } \\
14 \text { days/ } \\
14 \text { days }\end{array}$ & {$[68,117,118]$} \\
\hline & $\mathrm{CuO}$ & $\begin{array}{l}\text { 20W50/ } \\
\text { Engine oil }\end{array}$ & Ball milling & $\begin{array}{l}\text { For } 30 \text { days/ } \\
5 \text { days }\end{array}$ & {$[116,119]$} \\
\hline & $\begin{array}{l}\mathrm{hBN} / \mathrm{CNTs} / \\
\mathrm{CuO}, \mathrm{TiO}_{2}\end{array}$ & $\begin{array}{l}15 \mathrm{~W} 40 / \\
\text { transformer oil/ } \\
\text { water }\end{array}$ & $\begin{array}{l}\text { High shear } \\
\text { homogenization }\end{array}$ & $\begin{array}{l}\text { For } 14 \text { days/ } \\
1 \text { day/ } \\
8 \text { days, } 21 \text { days }\end{array}$ & {$[120-122]$} \\
\hline & $\begin{array}{l}\mathrm{SWCNHs} / \mathrm{CuO} / \\
\text { graphene }\end{array}$ & $\begin{array}{l}\text { Water/ } \\
\text { gear oil/ PAO4 }\end{array}$ & $\begin{array}{l}\text { Using surfactants } \\
\text { (SDS/OA/Span } 80)\end{array}$ & $\begin{array}{l}\text { For } 39 \text { days/ } 30 \text { days/ } \\
28 \text { days }\end{array}$ & {$[121,123,124]$} \\
\hline \multirow[b]{2}{*}{$\begin{array}{l}\text { Chemical } \\
\text { methods }\end{array}$} & $\begin{array}{l}\mathrm{ZrO}_{2} / \mathrm{Al}_{2} \mathrm{O}_{3} / \\
\text { graphite }\end{array}$ & $\begin{array}{l}\text { machine oil/ } \\
\text { Naphthenic oil }\end{array}$ & $\begin{array}{l}\text { Using silane coupling } \\
\text { agent (KH560/ KH570) }\end{array}$ & $\begin{array}{l}\text { For } 30 \text { days/ } \\
20 \text { days/ } \\
60 \text { days }\end{array}$ & {$[35,39,125]$} \\
\hline & $\begin{array}{l}\mathrm{SiO}_{2} / \mathrm{Ag} / \\
\mathrm{Cu} @ \mathrm{CNTs} / \\
\mathrm{WS}_{2} / \mathrm{MoS}_{2}\end{array}$ & $\begin{array}{l}\text { Liquid paraffin/ } \\
\text { PAO/ rapeseed } \\
\text { oil/ PAO6/ } \\
\text { PAO10 }\end{array}$ & $\begin{array}{l}\text { Using surface } \\
\text { modification agents } \\
\text { (OA/TBBT, C12/ PDA/ } \\
\text { oleyl amine/ NOM) }\end{array}$ & $\begin{array}{l}\text { For } 30 \text { days/ } \\
90 \text { days/ } \\
10 \text { days/ } \\
180 \text { days/ } \\
7 \text { days }\end{array}$ & [126-130] \\
\hline \multirow{2}{*}{$\begin{array}{l}\text { Self-disperse } \\
\text { d methods }\end{array}$} & $\begin{array}{l}\text { Crumpled Graphene } \\
\text { ball/ heRGO/ SRGO }\end{array}$ & $\begin{array}{l}\text { PAO4/ } \\
\text { PAO6/ } \\
\text { Hydraulic oil }\end{array}$ & Ultrasonication/ stirring & $\begin{array}{l}\text { For about } \\
1 \text { day/ } \\
4 \text { days/ } \\
10 \text { days }\end{array}$ & {$[131-133]$} \\
\hline & $\begin{array}{l}\mathrm{ZnO} @ \mathrm{G} / \\
\mathrm{WS}_{2} @ \mathrm{G} / \\
\mathrm{CeO}_{2} @ \mathrm{G} / \\
\mathrm{Ag} @ \mathrm{rGO}\end{array}$ & $\begin{array}{l}\text { Ester oil/ } \\
\text { PAO4/ } \\
\text { liquid paraffin/ } \\
\text { liquid paraffin }\end{array}$ & Ultrasonication & $\begin{array}{l}\text { For more than } 5 \text { days/ } \\
7 \text { days/ } \\
1 \text { day/ } \\
60 \text { days }\end{array}$ & {$[79,134-136]$} \\
\hline
\end{tabular}



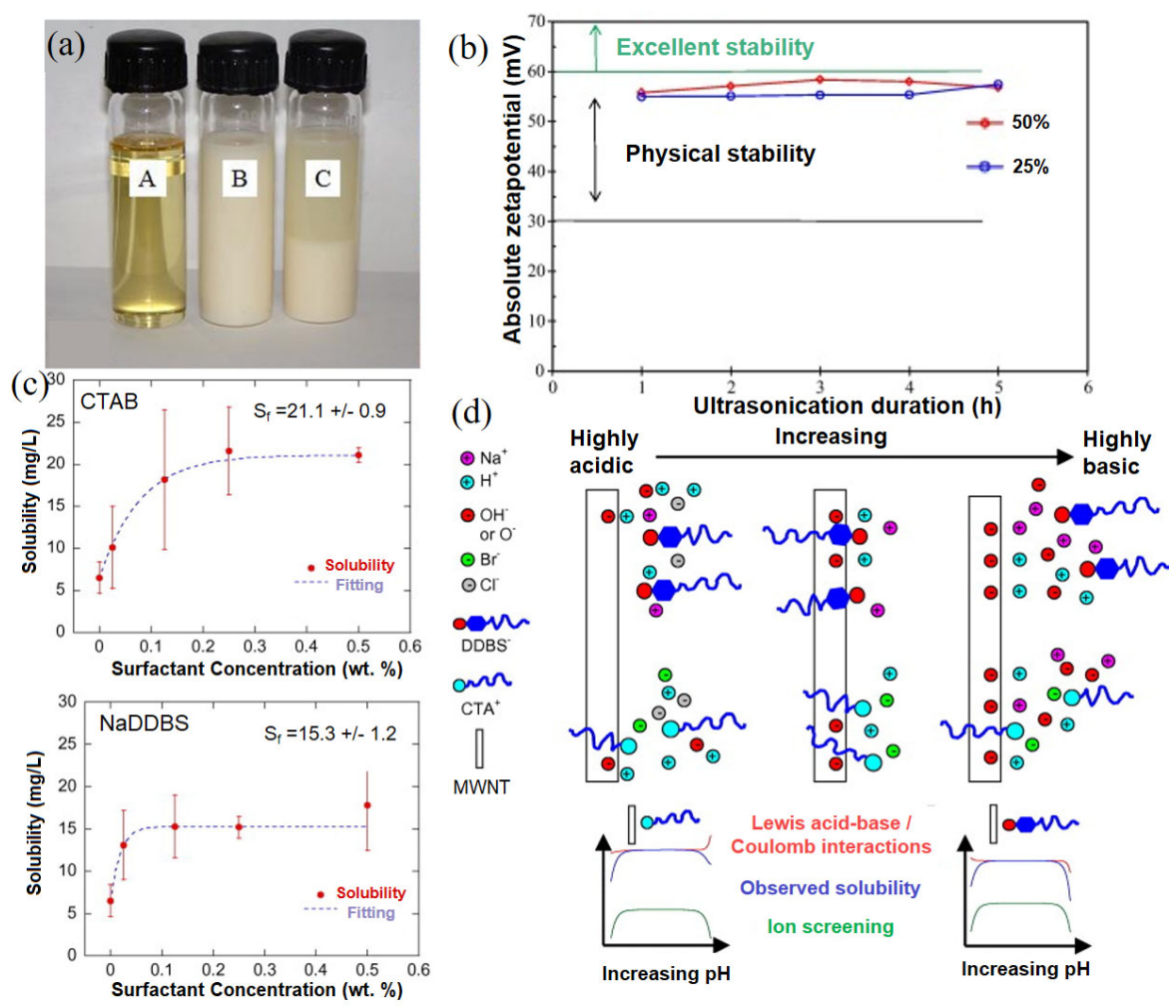

Fig. 5 (a) PTFE nanolubricants after 7 days of preparation (A-base oil, B-PTFE nanolubricant with 1-hour ultrasonication, C-PTFE nanolubricant with 30-min ultrasonication). Reproduced with permission from Ref. [68], (C) Elsevier, 2013. (b) Effect of ultrasonication on the dispersion stability of $\mathrm{Al}_{2} \mathrm{O}_{3}$. Reproduced with permission from Ref. [115], (C) Elsevier, 2015. (c) Nanotube dispersibility with varying surfactant concentrations for CTAB, NaDDBS, and (d) schematic representation of the effect of surfactants. Reproduced with permission from Ref. [137], C) Elsevier, 2011.

Moreover, high-pressure homogenization is effective in enhancing dispersion stability and it is simple to operate. Wan et al. [120] dispersed h-BN nanoparticles into SAE 15W40 with the assistance of high shear homogenizer. This work indicated that the suspension remained stable for more than 14 days. Other researches carried out by Fontes et al. [121] and Fedele et al. [122] have also confirmed that high shear homogenization was a useful method to prepare a stable and uniform dispersion of nanoparticles. In general, several physical methods above are always synthetically used to ensure the stability and uniformity of the nanoparticles in base lubricants.

Moreover, the use of surfactants is important to enhance the dispersion stability of nanoparticles during physical processes. Surfactant molecules adsorb onto the surface of nanoparticles and form a micelle-like structure to provide a physical "cushion" between colliding particles, thereby reducing the interaction of nanoparticles. There are four typical classes of surfactants: anionic (with negatively charged head groups), cationic (with positively charged head groups), non-ionic (without charged groups in its head or neutral), and amphoteric (with zwitterionic head groups) [138]. The effect of surfactants: sodium 4-dodecylbenzenesulfonate (NaDDBS), hexadecyl(trimethyl)azanium bromide (CTAB), oleic acid, sodium dodecyl sulfate (SDS), and span 80 on the improvement of dispersion stability was investigated in the following experiments. Clark et al. [137] investigated the effect of NaDDBS and $\mathrm{CTAB}$ as surfactants, as shown in Fig. 5(c). Surfactant molecules adsorbed on the surface of carbon nanotubes, which reinforced the interaction between nanoparticles and water, thereby inhibiting the aggregation of nanoparticles and significantly improving the dispersion stability. Ali et al. [139] dispersed $\mathrm{Al}_{2} \mathrm{O}_{3}$ and $\mathrm{TiO}_{2}$ nanoparticles into engine oil 5W30, in which oleic acid was used as surfactants. According to the results of dynamic light scattering, 
the peak diameters of these two nanoparticles had a little increase, which meant only a slight agglomeration occurred in the dispersion. Ali et al. [140] also confirmed the dispersion of $\mathrm{Al}_{2} \mathrm{O}_{3} @ \mathrm{TiO}_{2}$ nanocomposites remained stable for 14 days with the addition of oleic acid as surfactants. Another study carried out by Kole and Dey [123] indicated that $\mathrm{CuO}$ nanoparticles remained stable for 30 days in gear oil with the assistance of oleic acid as surfactants. SDS was used as surfactants to prepare the water-based suspension of single-wall carbon nanohorns (SWCNHs) in the research carried out by Laura et al. [121]. Zheng et al. [124] added span80 when preparing the dispersion of graphene, and the results revealed that there was no sedimentation in dispersion within 28 days after preparation. Huang et al. [141] dispersed graphene into liquid paraffin with the assistance of span 80 . The results revealed that the addition of span 80 improved the stability of suspensions in comparison with the suspensions without surfactants.

\subsubsection{Chemical methods}

Chemical methods mean using chemical agents to chemically modify the surfaces of nanoparticles for improving dispersion stability. Surface modification agents, including organic modification agents and silane coupling agents, mainly deal with the stabilization problem of inorganic nanoparticles in the base oil. The organic compounds used as modification agents usually comprise polar groups and long alkyl chains that can chemically adsorb onto the inorganic nanoparticles, which enables inorganic nanoparticles to be uniformly dispersed in an organic solvent. In addition, silane coupling agents, which have 1-3 alkoxy groups and 3-1 organic functional groups, are used to modify nanoparticle surfaces. With the assistance of surface modifiers, aggregation of nanoparticles is inhibited and nanolubricants can remain stable for a long time. Metallic particles with chemical modification exhibit enhanced dispersion stability in comparison with untreated particles. Xiong et al. [142] used tetradecyl hydroxamic acid as a modifier and synthesized oil-soluble $\mathrm{Cu}$ nanoparticles. The results showed that no signs of aggregation were found in lubricants. Sánchez-
López et al. [27] prepared tetrahydrofuran-modified $\mathrm{Pd}$ nanoparticles and toluene-modified Au nanoparticles. The research confirmed that both of them presented good dispersion stability. Peng et al. [128] used oleic acid to modify $\mathrm{SiO}_{2}$ nanoparticles and revealed that the suspension remained stable for more than 30 days. Ma et al. [39] modified $\mathrm{ZrO}_{2}$ nanoparticles with $\gamma$-(2,3-epoxypropoxy) propytrimethoxysilane (KH560) and found that the average diameter of nanoparticles in the suspension obviously decreased and there was no aggregation. Wu et al. [130] modified $\mathrm{MoS}_{2}$ nanosheets with n-Octadecyl mercaptan (NOM) and found that the suspension remained stable for 7 days as shown in Fig. 6(a). Other carbon materials such as carbon nanotubes and graphene nanosheets can also be dispersed uniformly and stably with surface modification. For instance, Chen et al. [143] modified carbon nanotubes by esterification reaction with fatty acid and achieved good dispersion stability of carbon nanotubes in liquid paraffin. Wang et al. [129] synthesized $\mathrm{Cu} @ \mathrm{CNT}$ composites with polydopamine (PDA) as a modifier and revealed the excellent dispersion stability of the nanocomposite (stable for 7 days) in comparison with carbon nanotubes (stable for 2 days), as shown in Fig. 6(b). In addition, the surface modification of graphene has been widely investigated. Hydrothermal-prepared graphene oxide as the precursor of graphene contains a large quantity of oxygen groups such as hydroxyl and carboxyl groups. These oxygen groups can be replaced by other functional groups during the surface modification process. What is more, these functional groups are chemically adsorbed on graphene after reduction, therefore, the dispersion stability can also be improved. Oleic acid, octadecyl amine, primary amine, amino acid, and amino siloxane can be used as the modifier of graphene [144-146]. Zhang et al. [146] synthesized graphene nanosheets with outstanding dispersion stability via modification of oleic acid at $80{ }^{\circ} \mathrm{C}$ for $3 \mathrm{~h}$. Han et al. [147] synthesized alkyl-functionalized graphene oxide and the results confirmed that the dispersibility of modified graphene oxide in poly alpha-olefin (PAO)4 was reinforced in comparison with that of unmodified graphene oxide, as shown in Fig. 7. 
Although nanoparticles with surface modification have significant improvement on dispersion stability, the introduction of atoms and functional groups may destroy the structure of nanoparticles and conceal the nature characteristics of nanoparticles. Therefore, it is of great importance to enhance the dispersion stability of nanoparticles and maintain the nature characteristics simultaneously.

\subsubsection{Self-dispersed methods}

Physical suspension methods are green, simple, and economical, and widely used in the previous research, but nanoparticles with physical treatment are prone to secondary agglomerating and being unstable in lubricants. Although chemical methods can significantly enhance the dispersion stability, the addition of chemical agents reduces the natural characteristics of nano additives and affects the tribological properties of nanolubricants at the same time. Therefore, it is necessary to develop self-dispersed methods to prepare a stable and uniform suspension. Current studies have found that the dispersion
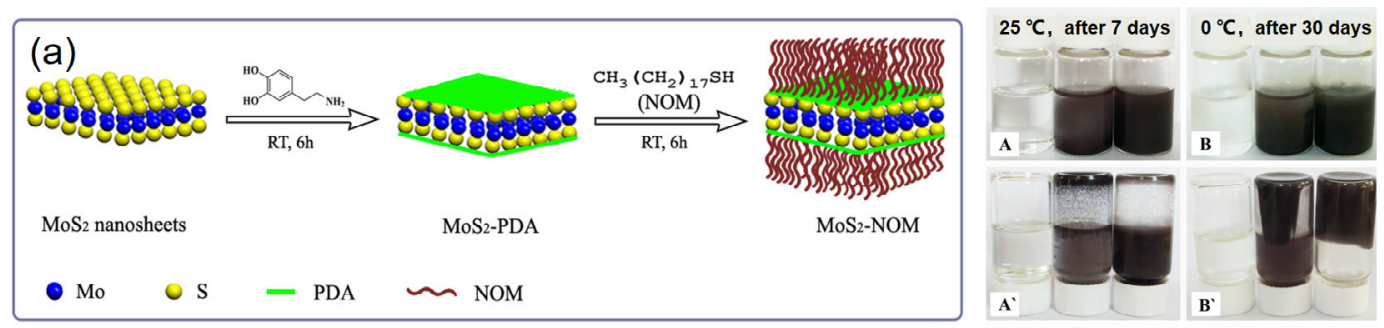

(b)

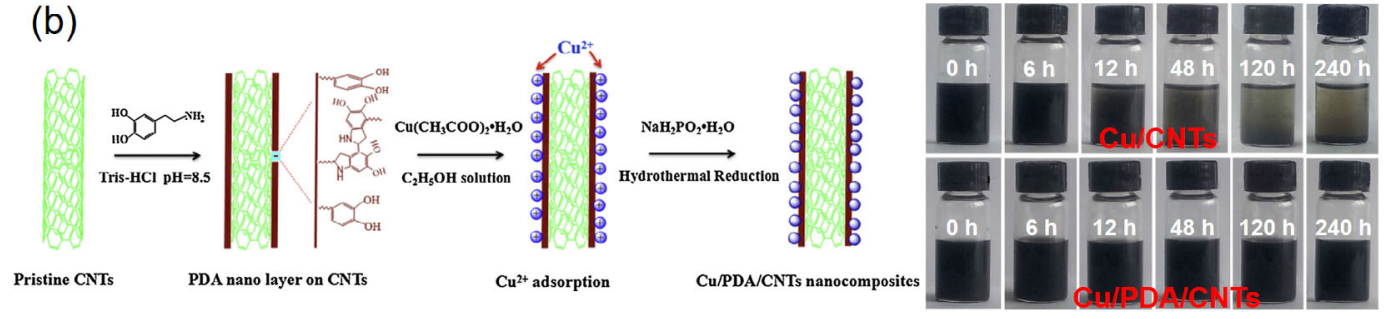

Fig. 6 (a) Preparation and dispersion stability of NOM modified $\mathrm{MoS}_{2}$ nanosheet. Reproduced with permission from Ref. [130], (C) American Chemical Society, 2018. (b) Preparation and dispersion stability of copper/carbon nanotube composite. Reproduced with permission from Ref. [129], (c) Elsevier, 2018.

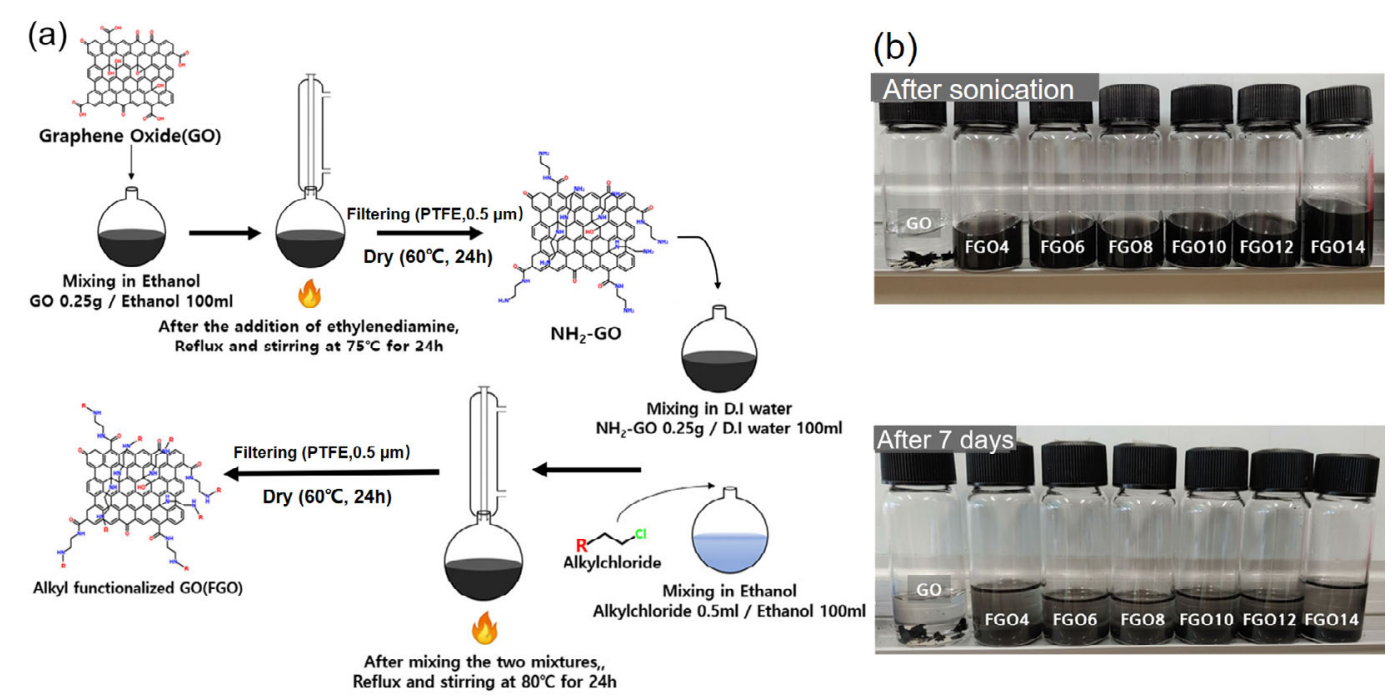

Fig. 7 (a) Preparation and (b) dispersion stability of alkyl-functionalized graphene oxide. Reproduced with permission from Ref. [147], (C) John Wiley and Sons, 2020. 
stability of nanoparticles can be enhanced via the structure regulation of nanoparticles. Dou et al. [131] prepared crumpled graphene balls by capillary compression is rapidly evaporating aerosol droplets of GO sheets. Furthermore, they compared the dispersion stability of four carbon additives (graphite, reduced graphene oxide, carbon black, and crumpled graphene balls) in PAO4. The results showed that after $20 \mathrm{~h}$, obvious sedimentation was observed in the other three suspensions except for crumpled graphene balls suspension, which confirmed that crumpled graphene balls had good self-dispersion properties. It is because the additives with crumpled and spherical shape can reduce the attraction between particles and prevent them from restacking, thereby inhibiting aggregation and enhancing dispersion stability. In addition, highly exfoliated graphene exhibits better dispersion stability than multilayer graphene, because of the high value of the specific surface area of highly exfoliated graphene which increases the interaction between graphene and lubricant molecules, enhances the steric hindrance, and prevents the restacking of graphene. Li et al. [132] exfoliated graphene with the assistance of $\mathrm{KOH}$ and investigated the dispersion stability. According to the research, the specific surface area (SSA) could be controlled via adjusting the weight ratio of $\mathrm{KOH}$ and GO. They also found that highly exfoliated reduced graphite oxide (heRGO) suspension remained stable for more than 4 days while obvious separation appeared in the suspension of graphene prepared without the assistance of $\mathrm{KOH}$ (tRGO) only after 2 days, which indicated that heRGO processed a more excellent self-dispersion characteristic in comparison with tRGO. The higher SSA value of heRGO $\left(829.5 \mathrm{~m}^{2} / \mathrm{g}\right)$ than that of tRGO $\left(384.5 \mathrm{~m}^{2} / \mathrm{g}\right)$ explained the superior dispersion stability. Zhao et al. [133] further prepared superhigh-exfoliated reduced graphene oxide (SRGO) and conducted tribological experiments on it, as shown in Fig. 8. The SSA of SRGO reached 1,665 $\mathrm{m}^{2} / \mathrm{g}$ which was over twice than that of above graphene. The results revealed that after 10 days, SRGO suspension was still stable while apparent sediment appeared in the dispersion of other graphene nanosheets. According to the above three types of research, structure plays an essential role in dispersion stability. The evolution of the chemical structure of nanoparticles can also have a significant improvement in the dispersion stability. Wang et al. [79] revealed that Ag@graphene with laser irradiation (L-Ag@rGO) exhibited more excellent self-dispersed properties than Ag@GO. The results also showed that the suspension of L-Ag@rGO remained stable for 60 days, while Ag@GO dispersion remained stable only for 30 days, as shown in Fig. 9. The research confirmed that the removal of oxygen
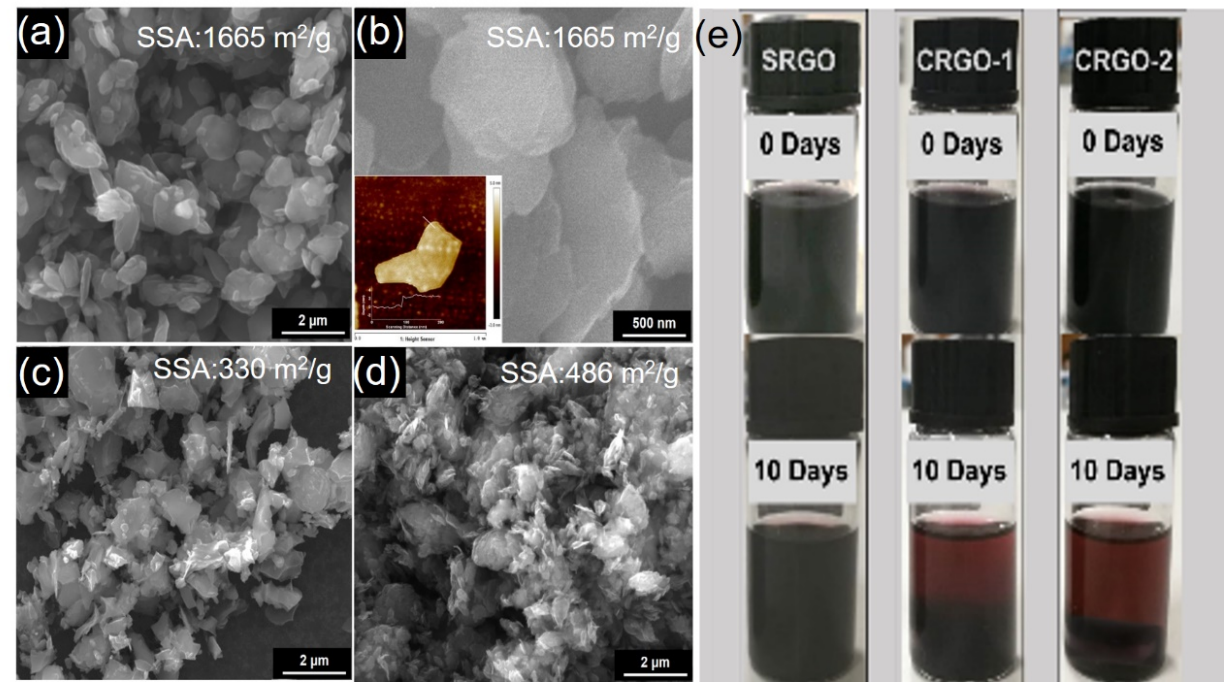

Fig. 8 SEM morphology images of (a, b) SRGO, (c) CRGO-1, and (d) CRGO-2. The inset of (b) is an AFM image of the SRGO nanosheets and the height profile is collected along the right line shown in the image. (e) Dispersion stability of nanolubricants with different graphene. Reproduced with permission from Ref. [133], (C) Elsevier, 2020. 

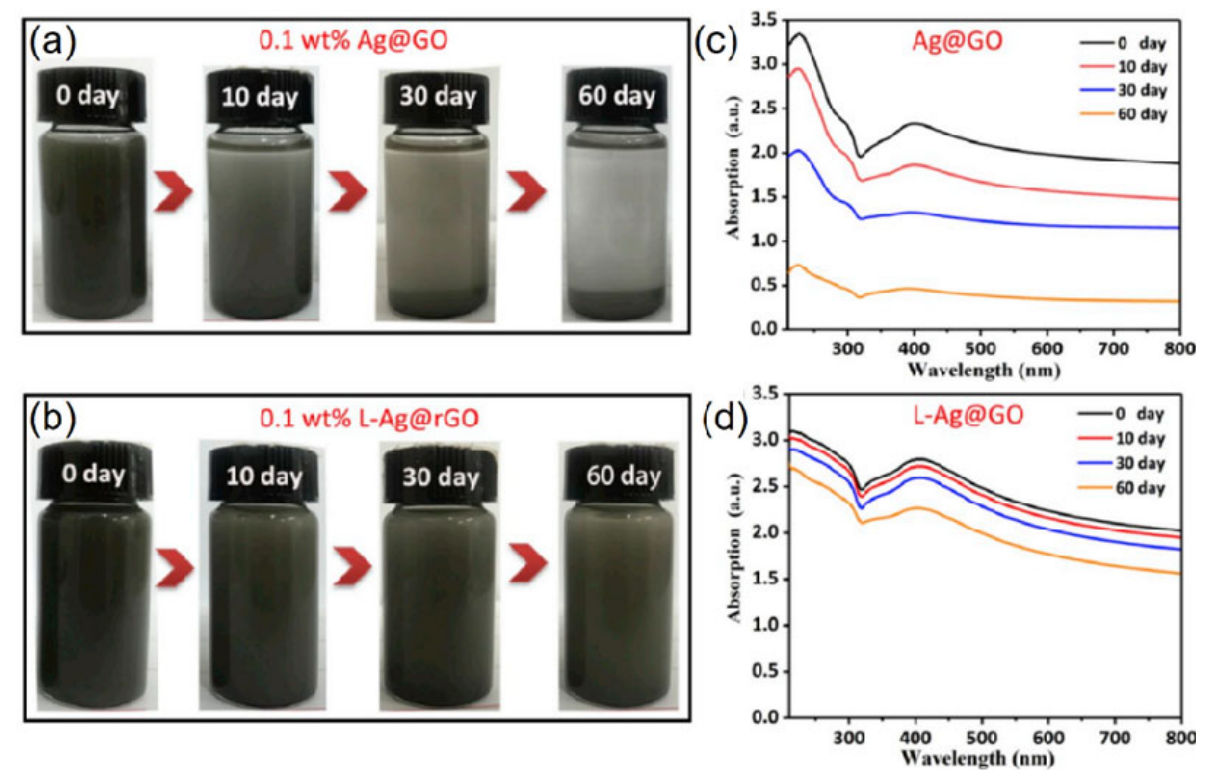

Fig. 9 Dispersion stability of (a) Ag@GO suspension and (b) L-Ag@rGO suspension; UV-vis absorption spectra of (c) $\mathrm{Ag} @ \mathrm{GO}$ and (d) L-Ag@rGO particles in a base oil for different static times. Reproduced with permission from Ref. [79], (C) Elsevier, 2020.

in graphene changed chemical structure of nanoparticles which improved the dispersion stability. In addition, the nanoparticles decorated on the surface of nanocomposites can significantly improve dispersion stability as well. Song et al. [76] prepared $\mathrm{Fe}_{2} \mathrm{O}_{3} @ \mathrm{G}$ nanolubricant additives and it is found that the agglomeration of the graphene nanosheets was prevented. And Zhao et al. [81] demonstrated that $\mathrm{Mn}_{3} \mathrm{O}_{4}$ nanoparticles loaded on the graphene surfaces obviously improved the dispersion stability because the nanoparticles can reduce the intimate contact areas between the nanoadditives and inhibit graphene agglomeration. Therefore, by the structure regulation of nanoparticles, the dispersion characteristics of nanoadditives in lubricating oil can be improved efficiently. It is of great significance to optimize the dispersion stability of nanolubricant additives by self-dispersed methods and to further study their lubrication performances and mechanisms.

\section{Lubrication mechanisms of nanolubricant additives}

The lubrication mechanisms of nanoparticles can be briefly concluded into five aspects: formation of tribofilm, rolling bearing effect, the transformation of microstructure, synergistic effect, and surface repairing effect. Table 3 shows the lubrication mechanisms of various nanolubricant additives.

\subsection{Formation of tribofilm}

Because of the high values of specific surface area and surface energy, nanoparticles are easy to form a protective film on the contact surfaces by adsorption or chemical reactions, as shown in Fig. 10. The formation of tribofilm can avoid direct metal-to-metal contacts and play an important role in lubrication. The polarity of molecules significantly influences the film formation. For instance, an enrichment effect in the Hertz contact region was observed when dispersing polar additive molecules into a nonpolar base oil, which can be explained by the interaction between polar additive molecules and the steel surface. However, there was no enrichment effect for nonpolar molecules dispersed into the nonpolar base oil and polar molecules dispersed into polar base oil [148]. Nanolubricant additives with low chemical activity such as copper, silver, and graphene always form a physical adsorption tribofilm. Desanker et al. [149] confirmed the physical adsorption film which was formed by deposited silver nanoparticles via a scanning electron microscope (SEM) and energy dispersive spectrometer (EDS) analyses. Apart from physical adsorption film, nanoparticles containing 
Table 3 Lubrication mechanisms of nanolubricant additives.

\begin{tabular}{|c|c|c|}
\hline Type & Additives & Lubrication mechanisms \\
\hline \multirow{13}{*}{$\begin{array}{l}\text { Nanometal-based } \\
\text { additive }\end{array}$} & $\mathrm{Cu}[23,25,150]$ & $\begin{array}{l}\text { Formation of tribofilm; rolling bearing effect; } \\
\text { surface repairing effect }\end{array}$ \\
\hline & $\operatorname{Ag}[21,24]$ & Formation of tribofilm, synergistic effect \\
\hline & $\mathrm{Ni}[29,151]$ & Formation of tribofilm; surface repairing effect \\
\hline & $\operatorname{Pd}[27,28]$ & Formation of tribofilm \\
\hline & $\mathrm{CuO}[152,153]$ & $\begin{array}{l}\text { Tribofilm formation; rolling bearing effect; } \\
\text { surface repairing effect }\end{array}$ \\
\hline & $\mathrm{Al}_{2} \mathrm{O}_{3}[35]$ & Formation of tribofilm; rolling bearing effect \\
\hline & $\mathrm{ZnO}[33,154]$ & Tribofilm formation; surface repairing effect \\
\hline & $\mathrm{TiO}_{2}[155-157]$ & $\begin{array}{l}\text { Formation of tribofilm; rolling bearing effect; } \\
\text { surface repairing effect }\end{array}$ \\
\hline & $\mathrm{MoS}_{2}[158,159]$ & Tribofilm formation; surface repairing effect \\
\hline & $\mathrm{WS}_{2}[160,161]$ & Formation of tribofilm; rolling bearing effect \\
\hline & $\mathrm{LaF}_{3}[53,54]$ & Tribofilm formation \\
\hline & $\mathrm{CaCO}_{3}[52]$ & Formation of tribofilm \\
\hline & $\mathrm{CeBO}_{3}[162]$ & Formation of tribofilm \\
\hline \multirow{4}{*}{$\begin{array}{l}\text { Nanocarbon-based } \\
\text { additive }\end{array}$} & Graphene $[163,164]$ & Tribofilm formation; transformation of microstructure \\
\hline & CNT [94] & $\begin{array}{l}\text { Tribofilm formation; rolling bearing effect; transformation of } \\
\text { microstructure }\end{array}$ \\
\hline & Diamond [91] & Rolling bearing effect \\
\hline & PTFE $[68]$ & Formation of tribofilm \\
\hline \multirow{8}{*}{$\begin{array}{l}\text { Nanocomposite-based } \\
\text { additive }\end{array}$} & $\mathrm{Cu} @ \mathrm{SiO}_{2}[72]$ & Tribofilm formation, surface repairing effect \\
\hline & $\mathrm{Al}_{2} \mathrm{O}_{3} @ \mathrm{SiO}_{2}[165]$ & Synergistic effect \\
\hline & $\mathrm{Cu} @ \mathrm{GO}[80]$ & Synergistic effect \\
\hline & $\mathrm{Au} @ \mathrm{GO}[166]$ & Synergistic effect \\
\hline & $\mathrm{Mn}_{3} \mathrm{O}_{4} @ \mathrm{G}[81]$ & Synergistic effect \\
\hline & GNS@MoS $[75]$ & Synergistic effect \\
\hline & SOCNTs@MoS 2 [167] & Formation of tribofilm; synergistic effect \\
\hline & $\mathrm{Co}\left(\mathrm{ReO}_{4}\right)_{2} @ \mathrm{MoS}_{2}[168]$ & Tribofilm formation \\
\hline
\end{tabular}

polar atoms are capable to form a more stable chemical tribofilm which is achieved by tribochemistry reaction during the friction process. Ratoi et al. [169] analyzed the components of the tribofilm formed by $W_{2}$. They revealed that the tribofilm could be mainly divided into four layers: the top layer consisted of exfoliated $\mathrm{WS}_{2}$ nanoparticles; the second layer contained $\mathrm{WS}_{2}, \mathrm{WO}_{3}$, iron oxide, and sulfide, $\mathrm{Fe}$ and $\mathrm{W}$; the third layer included $\mathrm{WO}_{3}$, Fe and W; and the bottom layer consisted of Fe and W. Chen et al. [162] investigated the tribological properties of $\mathrm{CeBO}_{3}$ nanoparticles and studied the lubrication mechanism. The research showed that the formation of tribofilm consisted of $\mathrm{B}_{2} \mathrm{O}_{3}, \mathrm{CeO}_{2}$, and $\mathrm{FeO}_{3}$ as the main mechanism, which explained the outstanding antifriction and antiwear performance. The lubrication mechanism of $\mathrm{CaCO}_{3}$ was also studied by Zhang et al. [52]. They indicated the formation of tribofilm containing $\mathrm{CaCO}_{3}, \mathrm{CaO}, \mathrm{Fe}_{2} \mathrm{O}_{3}$, and some organic compounds. Kumar et al. [69] found that the excellent tribological properties of PTFE were attributed to the formation of tribofilm of $\mathrm{FeF}_{2}$ on rubbing surfaces.

\subsection{Rolling bearing effect}

Nanoparticles with spherical shapes can roll between the asperities of friction surfaces, which transforms sliding friction to rolling friction at a micro-area interface, as shown in Fig. 11. Sia et al. [170] found 
(a)

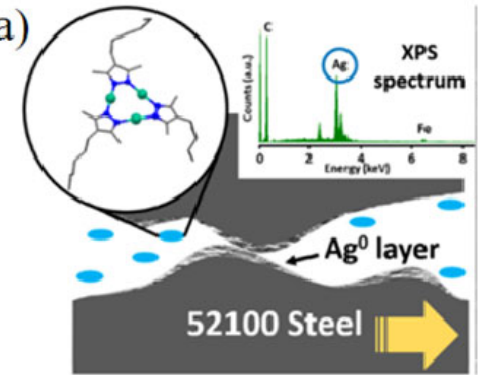

(b)

(c)

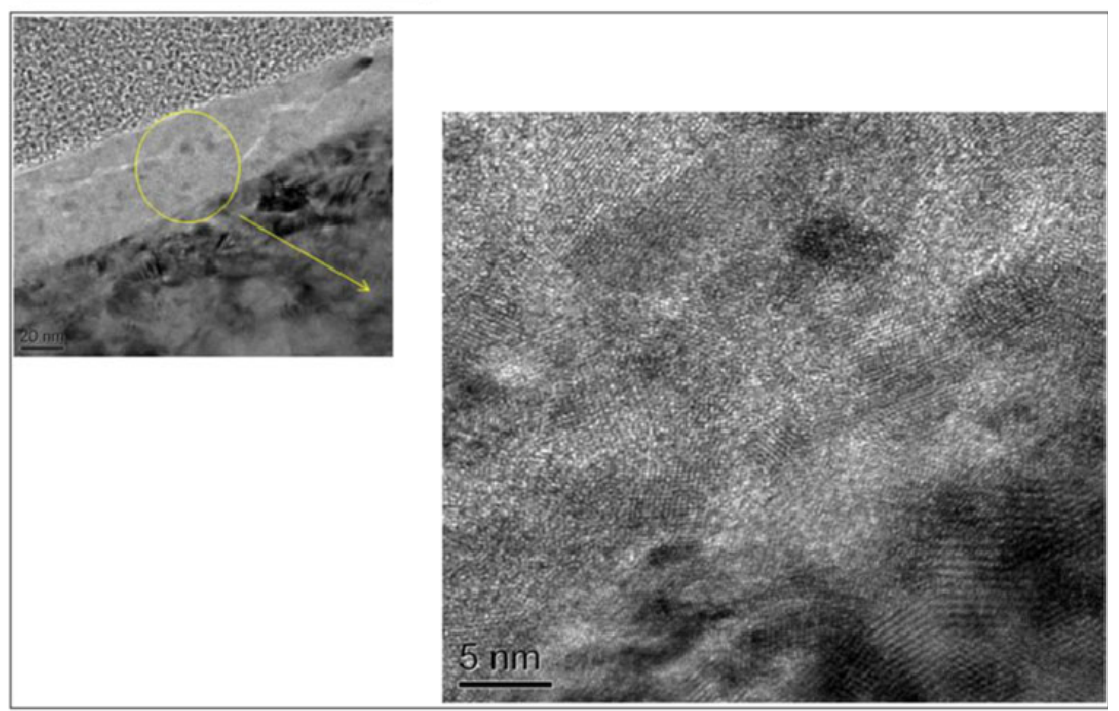

Fig. 10 (a) Model of physical adsorption film. Reproduced with permission from Ref. [149], ( ) American Chemical Society, 2016. (b) Model of $\mathrm{WS}_{2}$ chemical tribofilm. Reproduced with permission from Ref. [169], () Springer Nature, 2013. (c) SEM micrograph of $\mathrm{MoS}_{2}$ tribofilm. Reproduced with permission from Ref. [171], () John Wiley and Sons, 2016.

that $\mathrm{SiO}_{2}$ nanoparticles acted as rolling bearing during friction and exhibited friction-reduction and wear-resistance properties. Rapoport et al. [160] revealed that fullerene-like $\mathrm{WS}_{2}$ nanoparticles obviously enhanced the tribological properties, which could be explained by the slow release of $\mathrm{WS}_{2}$ nanoparticles from the matrix and their rolling effects on rubbing surfaces. Kim et al. [91] indicated that the friction-reduction properties of nanodiamond were possibly owing to its rolling effect. In addition, polymer nanoparticles can form a tribofilm on the contact surfaces and have the same function as ball bearing at low load during friction. However, when the applied load is high, the rolling bearing effect is prone to failure [93]. Sui et al. [172] investigated the tribological properties of hairy silica nanoparticles and it was found that the outstanding frictionreduction and wear-resistance performances were partly attributed to the rolling bearing effect. The research also implied that the rolling bearing effect was enhanced with the increase of size. Bao et al. [173] found that film thickness is an important factor affecting the lubrication mechanisms and they indicated that the rolling bearing effect was the dominant lubrication mechanism when the film thickness was an approach to the particle size. However, when the film is thin, nanoparticles tend
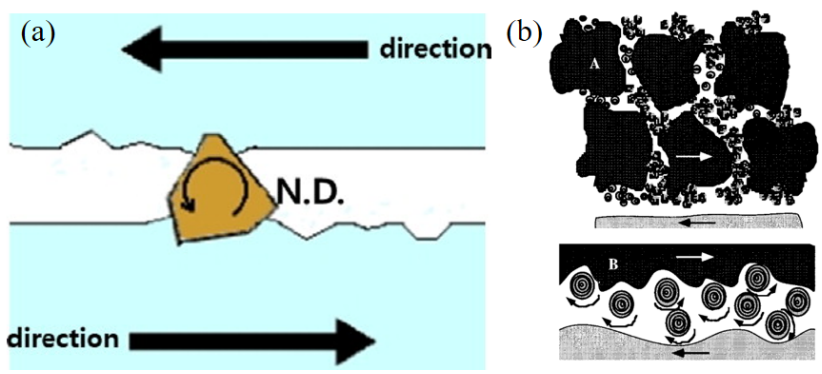

Fig. 11 (a) Rolling bearing effect of nanodiamond. Reproduced with permission from Ref. [91], (C) Elsevier, 2013. (b) Rolling bearing effect of fullerene-like $\mathrm{WS}_{2}$ nanoparticles. Reproduced with permission from Ref. [160], (C) American Chemical Society, 2001. 
to form a transfer film.

\subsection{Transformation of microstructure}

The microstructure is an important nature characteristic of nanoparticles such as carbon nanotubes, graphene, and nanodiamond. High pressure and heat during the friction process may destroy the original microstructure and produce a new microstructure. And the evolution of microstructure results in the variation of tribological performance. The microstructure of nanocarbon materials tends to be ordered during the friction process, thereby enhancing the antifriction and antiwear properties [174,175]. Joly-Pottuz et al. [92] revealed the transformation of fullerene to graphene during the tribological experiments and indicated that with the change of microstructure, a good lubrication effect was obtained. Zhang et al. [94] found long carbon nanotubes tended to be shortened when the applied load was low. The short nanotubes are easy to enter the contact surfaces to form a protective film, meanwhile, the intertwining of nanotubes is inhibited and the rolling effect is enhanced with the reduction of length. However, at high applied load, graphene-like components with lamellar structure are formed from original nanotubes, and excellent tribological properties are achieved, as shown in Fig. 12(a). According to the research carried out by Zhao et al. [164], highly exfoliated graphene tended to overlap and order under pressure and shearing forces, and then formed a stable and lamellar adsorption film parallel to the sliding direction on the contact surfaces, thereby significantly improving the tribological properties, as shown in Fig. 12(b). However, the frictional trend of originally oriented graphene is quite opposite. The graphene layers which were integrated and oriented originally were damaged during friction and further scratched the friction interfaces. After long- time friction, the microstructure of the graphene nanosheets becomes disordered, which leads to lubrication failure $[95,176]$. Therefore, the transformation of microstructure plays an important role in tribological properties, especially for nanocarbon-based additives.

\subsection{Synergistic effect}

Nanolubricant additives are not isolated in lubricating oil or grease, and they often cooperate with other additives, lubricating oils, and modified friction surfaces to achieve a synergistic effect. Ghaednia et al. [24] indicated that the excellent tribological properties of silver nanoparticles were attributed to the synergistic effect between silver nanoparticles and base lubricants. Jiao et al. [165] revealed that

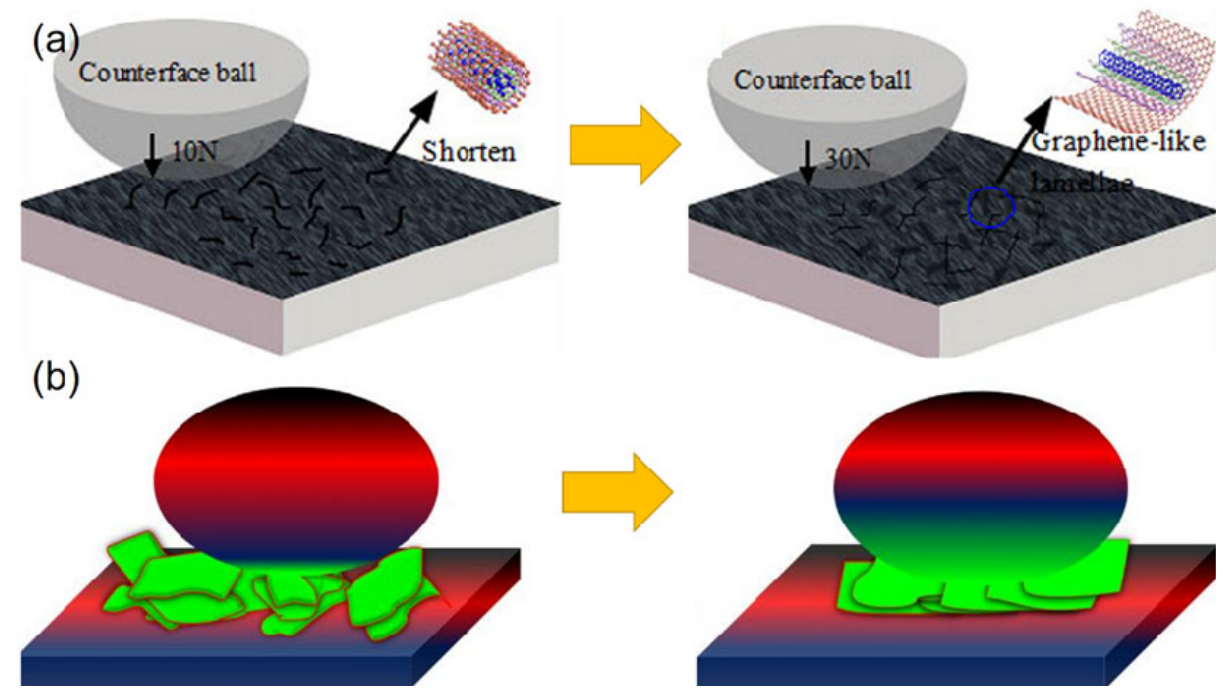

Fig. 12 (a) Transformation of CNTs to graphene under friction. Reproduced with permission from Ref. [94], (C) Elsevier, 2014. (b) The transformation of high-exfoliated graphene to graphite under friction. Reproduced with permission from Ref. [164], (c) Elsevier, 2018. 
$\mathrm{Al}_{2} \mathrm{O}_{3} @ \mathrm{SiO}_{2}$ nanocomposites had superior tribological properties to either $\mathrm{Al}_{2} \mathrm{O}_{3}$ or $\mathrm{SiO}_{2}$, which was because of the synergistic effect of these nanocomposites. Apart from nanocomposite-based lubricant additives, a synergistic effect can also be observed between nanolubricant additives and modified surfaces by certain surface treatments such as nitriding, coating and texturing [177-179]. Nanocomposite can enhance both dispersion stability and tribological properties. Further analyses have confirmed that the graphene nanosheets and nanoparticles have a synergistic effect by forming a composite-based tribofilm on the friction interfaces as shown in Fig. 13. The particles anchored on the graphene layers sometimes have the rolling bearing effect to further improve antifriction and antiwear performance as well. The synergistic effect of Cu@rGO nanoparticles was confirmed in the research carried out by Zhang et al. [180]. Meng et al. [166] revealed the excellent tribological properties of Au@GO nanocomposites and the lubrication mechanisms. They indicated that the Au@GO nanocomposites deposited on the contact surfaces and formed a physical protective film. Meanwhile, the nanocomposites also absorbed oil molecules to provide a good boundary lubricating state. Moreover, the released $\mathrm{Au}$ nanoparticles and ruptured or deformed GO fragments exhibited a synergistic lubricating effect simultaneously. Zhao et al. [81] studied $\mathrm{Mn}_{3} \mathrm{O}_{4} @$ graphene nanocomposites with a sandwich-like nanostructure and revealed that graphene nanosheets were easy to slide between layers under friction, and $\mathrm{Mn}_{3} \mathrm{O}_{4}$ nanoparticles rolled at meantime to further reduce friction and wear. A "slide-roll" physical lubrication model was proposed in the research.

\subsection{Surface repairing effect}

The rubbing surfaces are generally smooth, of which the asperities can contact with each other directly
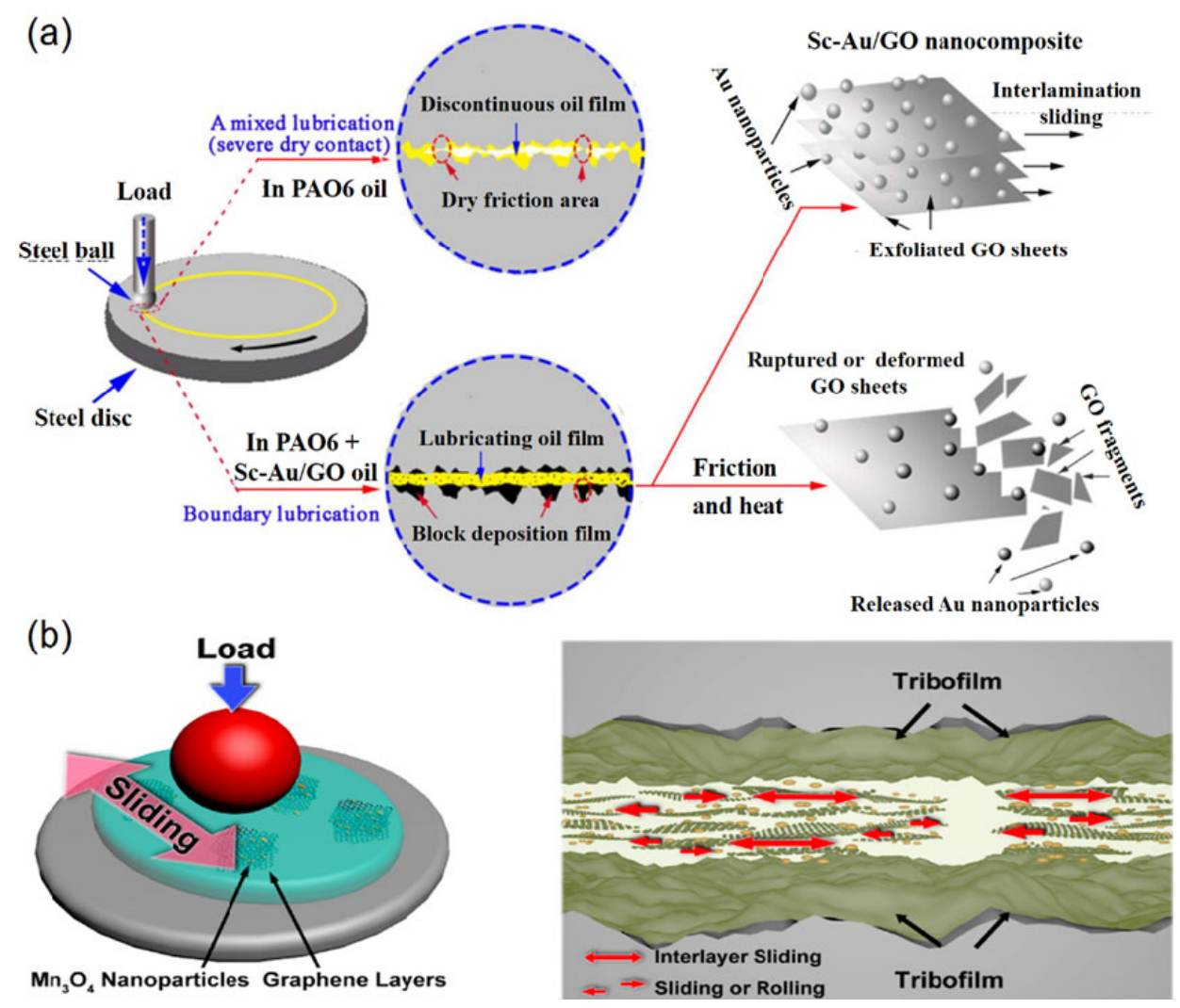

Fig. 13 (a) Synergistic effect model of Au@GO nanocomposites. Reproduced with permission from Ref. [166], C American Chemical Society, 2017. (b) The synergistic effect model of $\mathrm{Mn}_{3} \mathrm{O}_{4} @$ Graphene nanocomposites. Reproduced with permission from Ref. [81], (C) American Chemical Society, 2019. 
at boundary lubrication, thereby leading to high friction coefficient and wear rate. Nanoparticles can repair the friction-induced surface defects and improve the tribological properties, as shown in Fig. 14. Via surface repairing effect, the roughness of friction surfaces reduces considerably and the tribological properties are enhanced remarkably. Ali et al. [139] investigated the antifriction and antiwear properties of $\mathrm{Al}_{2} \mathrm{O}_{3}$ and $\mathrm{TiO}_{2}$ nanoparticles in engine oil. The results indicated that the high compressive pressure and temperature during friction promoted the sintering of nanoparticles on the surfaces and mended the scars and grooves, which resulted in the improvement of tribological properties. Çelik et al. [181] used SEM and EDS to analyze the characteristics of worn surfaces and found that h-BN nanoparticles completely filled the asperities by mending effect, thereby reducing the roughness of the worn surface and enhancing the antifriction and antiwear properties. The researches carried out by Gulzar et al. [182] revealed the excellent friction-reduction and wear-resistance properties of $\mathrm{TiO}_{2} @ \mathrm{SiO}_{2}$ nanocomposites. Based on the surface analyses via SEM, EDS, and AFM, they confirmed that the mending and polishing effect of $\mathrm{TiO}_{2} @ \mathrm{SiO}_{2}$ nanocomposites enhanced the friction surface. The surface repairing effect of nanoparticles is also mentioned in the research carried out by Choi et al. [183]. Deposited copper nanoparticles were detected on the grooves, and no nanoparticles were deposited on the asperities, which meant that copper nanoparticles mended the grooves and smoothed the friction surfaces. The research confirmed the surface repairing effect and led to an outstanding tribological performance. In contrast to the filling effect of nanoparticles, the asperities of the surfaces can be polished. Chu et al. [184] found that the addition of diamond nanoparticles played an essential role in resisting scuffing. The polishing effect of nanodiamond particles increased the surface hardness and the rubbing surfaces change to be very smooth.

\section{Conclusions and outlook}

It is of great significance to use nanomaterials as additives in lubricants for energy conservation, emission reduction, and environmental protection. According to the component elements of nanoparticles, there are three categories of nano lubricant additives: nanometal-based, nanocarbon-based, and nanocomposite-based additives, which have been systematically discussed in this review. With physically and/or chemically dispersed methods, a stable dispersion of nano additives in lubricants can be obtained. Moreover, via controlling the structure, nanoparticles can exhibit good self-dispersion properties. The review has also discussed the characteristic of different dispersed methods through contrastive analysis. By adding nano additives in lubricants, the tribological properties of lubricants can be significantly improved. Furthermore, the lubrication mechanisms of lubricant additives include the formation of tribofilm, rolling bearing effect, transformation of microstructure, synergistic, and repairing effects. Finally, to facilitate the use of nanomaterials as lubricant additives, future studies should take into consideration the following:

Firstly, traditional organic and inorganic lubricant additives always contain sulfur and phosphorus
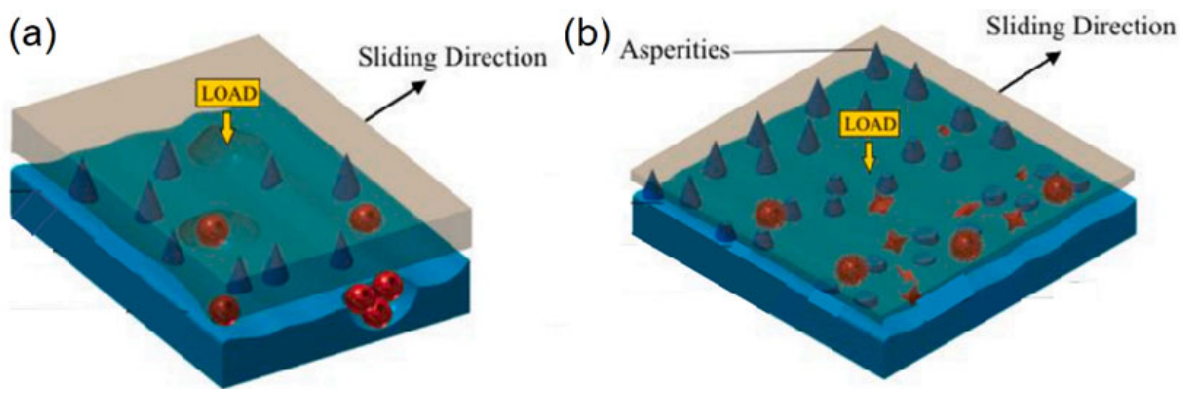

Fig. 14 (a) Model of surface repairing effect: mending effect and (b) polishing effect. Reproduced with permission from Ref. [69], (C) Elsevier, 2020. 
components, which easily releases SAPS and cause environmental pollution. Thus, it is essential to develop green and stable lubrication nanomaterials, and among these materials, nanocarbon-based, especially for graphene and graphene-like nanomaterials are regarded as potential candidates. Secondly, dispersion stability as the premise of practical applications is of great importance. But there are still difficulties in enhancing the dispersion stability of nanolubricant additives. Nanoparticles with physical treatment are prone to reaggregation. Chemical modification may conceal the natural characteristics of nanoparticles and chemical modifiers are prone to be degraded during friction. Therefore, further researches should be conducted to improve dispersion methods. And it seems to be the development trend of self-dispersed methods, which needs no modifiers and displays good dispersion stability. Furthermore, the agglomeration behavior of nanoparticle/lubricant dispersion during the friction process has not been studied yet, because the exploration methods of dispersion stability are mainly from offline processes such as optical microscopes and ultraviolet (UV) spectrophotometry, which cannot reveal the real state of nanoparticles in the lubricant. Therefore, Online exploration of dispersion is urgently needed. Finally, it is very important to study new lubricant additives under extreme friction conditions. With the rapid development of advanced industrial equipment, the work conditions of machinery meet extreme conditions such as high-pressure, high speed, and high temperature. Many highefficiency lubricant additives will decompose at $150{ }^{\circ} \mathrm{C}$ and their flash points are not more than $100{ }^{\circ} \mathrm{C}$. The applications of lubricant additives are still limited to a temperature of $1,000{ }^{\circ} \mathrm{C}$ and a load of 3,000 N. Therefore, exploring new lubricant additives with high tribological performance especially under extreme conditions will be the focus of basic researches and applications in future.

\section{Acknowledgments}

This work is supported by the National Natural Science Foundation of China (Grant No. 51905027), the National Key R\&D Program of China (2018YFB-
2000801), the Fundamental Research Funds for the Central Universities (BUCTRC201908), the Tribology Science Fund of State Key Laboratory of Tribology (SKLTKF18A02), and the Swedish Research Council for Environment, Agricultural Sciences and Spatial Planning (Formas Nos. 2016-01098 and 2019-00904), and the Swedish Research Council (No. 2019-04941).

Open Access This article is licensed under a Creative Commons Attribution 4.0 International License, which permits use, sharing, adaptation, distribution and reproduction in any medium or format, as long as you give appropriate credit to the original author(s) and the source, provide a link to the Creative Commons licence, and indicate if changes were made.

The images or other third party material in this article are included in the article's Creative Commons licence, unless indicated otherwise in a credit line to the material. If material is not included in the article's Creative Commons licence and your intended use is not permitted by statutory regulation or exceeds the permitted use, you will need to obtain permission directly from the copyright holder.

To view a copy of this licence, visit http://creativecommons.org/licenses/by/4.0/.

\section{References}

[1] Holmberg K, Erdemir A. The impact of tribology on energy use and $\mathrm{CO}_{2}$ emission globally and in combustion engine and electric cars. Tribol Int 135: 389-396 (2019)

[2] He F, Xie G X, Luo J B. Electrical bearing failures in electric vehicles. Friction 8(1): 4-28 (2020)

[3] Holmberg K, Erdemir A. Influence of tribology on global energy consumption, costs and emissions. Friction 5(3): 263-284 (2017)

[4] Holmberg K, Andersson P, Nylund N-O, Mäkelä K, Erdemir A. Global energy consumption due to friction in trucks and buses. Tribol Int 78: 94-114 (2014)

[5] Luo J B, Zhou X. Superlubricitive engineering-Future industry nearly getting rid of wear and frictional energy consumption. Friction 8(4): 643-665 (2020)

[6] Wang W, He Y Y, Zhao J, Mao J Y, Hu Y T, Luo J B. Optimization of groove texture profile to improve hydrodynamic lubrication performance: Theory and experiments. Friction 8(1): 83-94 (2020) 
[7] Xiao J K, Wu Y Q, Zhang W, Chen J, Zhang C. Friction of metal-matrix self-lubricating composites: Relationships among lubricant content, lubricating film coverage, and friction coefficient. Friction 8(3): 517-530 (2020)

[8] Braceras I, Ibáñez I, Dominguez-Meister S, Velasco X, Brizuela M, Garmendia I. Electro-tribological properties of diamond like carbon coatings. Friction 8(2): 451-461 (2020)

[9] Hwang Y H, Myung B S, Kim H J. Study on frictional behavior of carbon nanotube thin films with respect to surface condition. Friction 6(4): 432-442 (2018)

[10] Myshkin N, Kovalev A. Adhesion and surface forces in polymer tribology-A review. Friction 6(2): 143-155 (2018)

[11] Wang Z Q, Ni J, Gao D R. Combined effect of the use of carbon fiber and seawater and the molecular structure on the tribological behavior of polymer materials. Friction 6(2): 183-194 (2018)

[12] Hua J, Björling M, Larsson o, Shi Y J. Controllable Friction of Green Ionic Liquids via Environmental Humidity. Adv Eng Mater 22(5): 1901253 (2020)

[13] Spikes H. Low- and zero-sulphated ash, phosphorus and sulphur anti-wear additives for engine oils. Lubricat Sci 20(2): 103-136 (2008)

[14] Huang G W, Yu Q L, Ma Z F, Cai M R, Zhou F, Liu W M. Oil-soluble ionic liquids as antiwear and extreme pressure additives in poly- $\alpha$-olefin for steel/steel contacts. Friction 7(1): 18-31 (2019)

[15] Jiang C, Li W M, Nian J Y, Lou W J, Wang X B. Tribological evaluation of environmentally friendly ionic liquids derived from renewable biomaterials. Friction 6(2): 208-218 (2018)

[16] Uflyand I E, Zhinzhilo V A, Burlakova V E. Metal-containing nanomaterials as lubricant additives: State-of-the-art and future development. Friction 7(2): 93-116 (2019)

[17] Hisakado T, Tsukizoe T, Yoshikawa H. Lubrication Mechanism of Solid Lubricants in Oils. J Lubricat Technol 105(2): 245-252 (1983)

[18] Zhou J F, Yang J J, Zhang Z J, Liu W M, Xue Q J. Study on the structure and tribological properties of surface-modified $\mathrm{Cu}$ nanoparticles. Mater Res Bull 34(9): 1361-1367 (1999)

[19] Tarasov S, Kolubaev A, Belyaev S, Lerner M, Tepper F. Study of friction reduction by nanocopper additives to motor oil. Wear 252(1-2): 63-69 (2002)

[20] Zhao Y B, Zhang Z J, Dang H X. Synthesis of In-Sn alloy nanoparticles by a solution dispersion method. Mater Chem 14(3): 299-302 (2004)

[21] Ma J Q, Mo Y F, Bai M W. Effect of Ag nanoparticles additive on the tribological behavior of multialkylated cyclopentanes (MACs). Wear 266 (7-8): 627-631 (2009)

[22] Yu H L, Xu Y, Shi P J, Xu B S, Wang X L, Liu Q. Tribological properties and lubricating mechanisms of $\mathrm{Cu}$ nanoparticles in lubricant. Trans Nonferrous Met Soc China 18(3): 636-641 (2008)

[23] Wang X L, Y.L.Yin, G.N.Zhang, Wang W Y, Zhao K K. Study on Antiwear and Repairing Performances about Mass of Nano-copper Lubricating Additives to 45 Steel. Phys Procedia 50: 466-472 (2013)

[24] Ghaednia H, Hossain M S, Jackson R L. Tribological Performance of Silver Nanoparticle-Enhanced Polyethylene Glycol Lubricants. Tribol Trans 59(4): 585-592 (2016)

[25] Padgurskas J, Rukuiza R, Prosyčevas I, Kreivaitis R. Tribological properties of lubricant additives of $\mathrm{Fe}, \mathrm{Cu}$ and Co nanoparticles. Tribol Int 60: 224-232 (2013)

[26] Zhang S W, Hu L T, Feng D P, Wang H Z. Anti-wear and friction-reduction mechanism of $\mathrm{Sn}$ and $\mathrm{Fe}$ nanoparticles as additives of multialkylated cyclopentanes under vacuum condition. Vacuum 87: 75-80 (2013)

[27] Sánchez-López J C, Abad M D, Kolodziejczyk L, Guerrero E, Fernández A. Surface-modified Pd and Au nanoparticles for anti-wear applications. Tribol Int 44(6): 720-726 (2011)

[28] Abad M D, Sánchez-López J C. Tribological properties of surface-modified $\mathrm{Pd}$ nanoparticles for electrical contacts. Wear 297(1-2): 943-951 (2013)

[29] Chou R, Battez A H, Cabello J J, Viesca J L, Osorio A, Sagastume A. Tribological behavior of polyalphaolefin with the addition of nickel nanoparticles. Tribol Int 43(12): 2327-2332 (2010)

[30] Ghaednia H, Jackson R L, Khodadadi J M. Experimental analysis of stable $\mathrm{CuO}$ nanoparticle enhanced lubricants $J$ Exp Nanosci 10(1): 1-18 (2013)

[31] Thottackkad M V, Perikinalil R K, Kumarapillai P N. Experimental evaluation on the tribological properties of coconut oil by the addition of $\mathrm{CuO}$ nanoparticles. Int J Precis Eng Manuf 13(1): 111-116 (2012)

[32] Prakash E, Siva K K, Muthu K K. Experimental studies on vibration characteristics on ball bearing operated with copper oxide nano particle mixed lubricant. Int $J$ En Technol 5(5): 4127-4130 (2013)

[33] Xue W G, Zhao Z H, Wang P, Jin Z L, Xu X H, Zhou X G. Performance study of zinc oxide nanoparticles for lubricant oil. Adv Mater Res 1118: 195-204 (2015)

[34] Harta I C, Owens K, De Jesús Santiago S, Schall D, Thrush S, Barber G, Zou Q. Tribological Performance of ZnO-oil Nanofluids at Elevated Temperatures. SAE Int J Fuels Lubr 6(1): 126-131 (2013)

[35] Luo T, Wei $X$ W, Huang $X$, Huang L, Yang F. 
Tribological properties of $\mathrm{Al}_{2} \mathrm{O}_{3}$ nanoparticles as lubricating oil additives. Ceram Int 40(5): 7143-7149 (2014)

[36] Chang H, Li Z Y, Kao M J, Huang K D, Wu H M. Tribological property of $\mathrm{TiO}_{2}$ nanolubricant on piston and cylinder surfaces. J Alloys Compd 495(2): 481-484 (2010)

[37] Arumugam S, Sriram G. Preliminary Study of nano- and microscale $\mathrm{TiO}_{2}$ additives on tribological behavior of chemically modified rapeseed oil. Tribol Trans 56(5): 797-805 (2013)

[38] Sharma A K, Tiwari A K, Singh R K, Dixit A R. Tribological Investigation of $\mathrm{TiO}_{2}$ nanoparticle based cutting fluid in machining under minimum quantity lubrication (MQL). Mater Today Proc 3(6): 2155-2162 (2016)

[39] Ma S Y, Zheng S H, Cao D X, Guo H N. Anti-wear and friction performance of $\mathrm{ZrO}_{2}$ nanoparticles as lubricant additive. Particuology 8(5): 468-472 (2010)

[40] Al-Samarai R A, Al-Douri Y, Haftirman, Ahmad K R. Tribological properties of $\mathrm{WS}_{2}$ nanoparticles lubricants on aluminum-silicon alloy and carbon steels. Walailak $J$ Sci Technol 10(3): 277-287 (2013)

[41] Rengifo S, Zhang C, Harimkar S, Boesl B, Agarwal A. Effect of $\mathrm{WS}_{2}$ addition on tribological behavior of aluminum at room and elevated temperatures. Tribol Lett 65(3): 24 (2017)

[42] Zhang X H, Xu H X, Wang J T, Ye X, Lei W N, Xue M Q, Tang H, Li C S. Synthesis of ultrathin WS2 nanosheets and their tribological properties as lubricant additives. Nanoscale Res Lett 11(1): 442 (2016)

[43] Nallasamy P, Saravanakumar N, Nagendran S, Suriya E $\mathrm{M}$, Yashwant D. Tribological investigations on $\mathrm{MoS}_{2}$-based nanolubricant for machine tool slideways. Proc Inst Mech Eng J J Eng Tribol 229(5): 559-567 (2014)

[44] Yi M R, Zhang C H. The synthesis of two-dimensional $\mathrm{MoS}_{2}$ nanosheets with enhanced tribological properties as oil additives. $R S C A d v$ 8(17): 9564-9573 (2018)

[45] Zhang B M, Sun J L. Tribological performances of multilayer- $\mathrm{MoS}_{2}$ nanoparticles in water-based lubricating fluid. IOP Conf Ser Mater Sci Eng 182: 012023 (2017)

[46] Ky D L C, Tran Khac B-C, Le C T, Kim Y S, Chung $\mathrm{K}-\mathrm{H}$. Friction characteristics of mechanically exfoliated and CVD-grown single-layer $\mathrm{MoS}_{2}$. Friction 6(4): 395-406 (2017)

[47] Chen L J, Zhu D Y. Preparation and tribological properties of unmodified and oleic acid-modified $\mathrm{CuS}$ nanorods as lubricating oil additives. Ceram Int 43(5): 4246-4251 (2017)

[48] Wang L B, Gao Y P, Li Z Y, Zhou A G, Li P. Preparation and tribological properties of surface-modified $\mathrm{ZnS}$ nanoparticles. Lubricat Sci 27(4): 241-250 (2015)

[49] Zhao F Y, Bai Z M, Fu Y, Zhao D, Yan C M. Tribological properties of serpentine, $\mathrm{La}(\mathrm{OH})_{3}$ and their composite particles as lubricant additives. Wear 288: 72-77 (2012)

[50] Wang H D, Liu Y H, Chen Z, Wu B B, Xu S L, Luo J B. Layered double hydroxide nanoplatelets with excellent tribological properties under high contact pressure as water-based lubricant additives. Sci Rep 6: 22748 (2016)

[51] Wang H D, Liu Y H, Guo F M, Sheng H P, Xia K L, Liu W R, Wen J G, Shi Y J, Erdemir A, Luo J B. Catalytically active oil-based lubricant additives enabled by calcining $\mathrm{Ni}-\mathrm{Al}$ layered double hydroxides. J Phys Chem Lett 11(1): 113-120 (2020)

[52] Zhang M, Wang X B, Fu X S, Xia Y Q. Performance and anti-wear mechanism of $\mathrm{CaCO} 3$ nanoparticles as a green additive in poly-alpha-olefin. Tribol Int 42(7): 1029-1039 (2009)

[53] Zhang M, Wang X B, Liu W M. Tribological behavior of LaF3 nanoparticles as additives in poly-alpha-olefin. Ind Lubr Tribol 65(4): 226-235 (2013)

[54] Hou X, He J, Yu L G, Li Z W, Zhang Z J, Zhang P Y. Preparation and tribological properties of fluorosilane surface-modified lanthanum trifluoride nanoparticles as additive of fluoro silicone oil. Appl Surf Sci 316: 515-523 (2014)

[55] Li Z W, Hou X, Yu L G, Zhang Z J, Zhang P Y. Preparation of lanthanum trifluoride nanoparticles surface-capped by tributyl phosphate and evaluation of their tribological properties as lubricant additive in liquid paraffin. Appl Surf Sci 292: 971-977 (2014)

[56] He X L, Xiao H P, Choi H, Díaz A, Mosby B, Clearfield A, Liang H. $\alpha$-Zirconium phosphate nanoplatelets as lubricant additives. Colloids Surf A Physicochem Eng Aspects 452: 32-38 (2014)

[57] Li J S, Hao L F, Xu X H, Zhang L, Ren T H. Preparation, characterization and tribological evaluation of calcium borate nanoparticles as lubricant additives. Adv Mater Res 148-149: 1047-1056 (2010)

[58] Huang Y, Han S, Liu S Z, Wang Y H, Li J S. Preparation and tribological properties of surface-modified calcium borate nanoparticles as additive in lubricating oil. Ind Lubr Tribol 66 (1): 143-150 (2014)

[59] Lv Y X, Zhao X C, Cheng J W, Liu Y, Li H. The study on the reducing friction and anti-wear performance of zinc phosphate nanoparticles as lubrication additives. Mater Sci Forum 749: 211-216 (2013)

[60] Peng D X, Kang Y, Chen C H, Chen S K, Shu F C. The tribological behavior of modified diamond nanoparticles in liquid paraffin. Ind Lubr Tribol 61(4): 213-219 (2009) 
[61] Peng D X, Kang Y, Hwang R M, Shyr S S, Chang Y P. Tribological properties of diamond and $\mathrm{SiO}_{2}$ nanoparticles added in paraffin. Tribol Int 42(6): 911-917 (2009)

[62] Ku B C, Han Y C, Lee J E, Lee J K, Park S H, Hwang Y J. Tribological effects of fullerene (C60) nanoparticles added in mineral lubricants according to its viscosity. Int J Precis Eng Manuf 11(4): 607-611 (2010)

[63] Liu H T, Ji H M, Hong H P, Hammad Y. Tribological properties of carbon nanotube grease. Ind Lubr Tribol 66(5): 579-583 (2014)

[64] Bhaumik S, Prabhu S, Singh K J. Analysis of tribological behavior of carbon nanotube based industrial mineral gear oil $250 \mathrm{cSt}$ viscosity. Adv Tribol 2014: 341365 (2014)

[65] Mao J Y, Chen G Y, Zhao J, He Y Y, Luo J B. An investigation on the tribological behaviors of steel/copper and steel/steel friction pairs via lubrication with a graphene additive. Friction 9(2): 228-238 (2021)

[66] Xie H M, Jiang B, Dai J H, Peng C, Li C X, Li Q, Pan F S. Tribological behaviors of graphene and graphene oxide as water-based lubricant additives for magnesium alloy/steel contacts. Materials 11(2): 206 (2018)

[67] Yang J, Xia Y F, Song H J, Chen B B, Zhang Z Z. Synthesis of the liquid-like graphene with excellent tribological properties. Tribol Int 105: 118-124 (2017)

[68] Kumar D M, Bijwe J, Ramakumar S S V. PTFE based nano-lubricants. Wear 306 (1-2): 80-88 (2013)

[69] Kumar N, Saini V, Bijwe J. Performance properties of lithium greases with PTFE particles as additive: Controlling parameter-size or shape? Tribol Int 148: 106302 (2020)

[70] Wang J M, Wang J H, Li C S, Zhao G Q, Wang X B. Tribological performance of poly(sodium 4-styrenesulphonate) as additive in water-glycol hydraulic fluid. Lubricat Sci 24(3): 140-151 (2012)

[71] Tu T T, Wang W X, Wan Y, Pu J B. Tribology properties of the aqueous solution of polyvinylpyrrolidone. Mater Sci 4 (3): 103-110 (2014)

[72] Zhang C L, Zhang S M, Yu L G, Zhang Z J, Wu Z S, Zhang $\mathrm{P}$ Y. Preparation and tribological properties of water-soluble copper/silica nanocomposite as a water-based lubricant additive. Appl Surf Sci 259: 824-830 (2012)

[73] Luo T, Wei X W, Zhao H Y, Cai G Y, Zheng X Y. Tribology properties of $\mathrm{Al}_{2} \mathrm{O}_{3} / \mathrm{TiO}_{2}$ nanocomposites as lubricant additives. Ceram Int 40(7): 10103-10109 (2014)

[74] Jia X H, Huang J, Li Y, Yang J, Song H J. Monodisperse $\mathrm{Cu}$ nanoparticles $@ \mathrm{MoS}_{2}$ nanosheets as a lubricant additive for improved tribological properties. Appl Surf Sci 494: 430-439 (2019)
[75] Song W, Yan J C, Ji H B. Fabrication of GNS/MoS composite with different morphology and its tribological performance as a lubricant additive. Appl Surf Sci 469: 226-235 (2019)

[76] Song H J, Jia X H, Li N, Yang X F, Tang H. Synthesis of $\alpha-\mathrm{Fe}_{2} \mathrm{O}_{3}$ nanorod/graphene oxide composites and their tribological properties. J Mater Chem 22(3): 895-902 (2012)

[77] Zhang M S, Chen B B, Tang H, Tang G G, Li C S, Chen L, Zhang H M, Zhang Q. Hydrothermal synthesis and tribological properties of $\mathrm{FeS}_{2}$ (pyrite)/reduced graphene oxide heterojunction. RSC $A d v$ 5(2): 1417-1423 (2015)

[78] Meng Y, Su F H, Chen Y Z. Supercritical fluid synthesis and tribological applications of silver nanoparticle-decorated graphene in engine oil nanofluid. Sci Rep 6: 31246 (2016)

[79] Wang L, Gong P W, Li W, Luo T, Cao B Q. Mono-dispersed Ag/Graphene nanocomposite as lubricant additive to reduce friction and wear. Tribol Int 146: 106228 (2020)

[80] Meng Y, Su F H, Chen Y Z. Synthesis of nano- $\mathrm{Cu} /$ graphene oxide composites by supercritical $\mathrm{CO}_{2}$-assisted deposition as a novel material for reducing friction and wear. Chem Eng J 281: 11-19 (2015)

[81] Zhao J, Li Y R, He Y Y, Luo J B. In Situ Green Synthesis of the New Sandwichlike Nanostructure of $\mathrm{Mn}_{3} \mathrm{O}_{4} /$ Graphene as Lubricant Additives. ACS Appl Mater Interfaces 11(40): 36931-36938 (2019)

[82] Pan Z H, Wang T C, Chen L, Idziak S, Huang Z H, Zhao $\mathrm{B} X$. Effects of rare earth oxide additive on surface and tribological properties of polyimide composites. Appl Surf Sci 416: 536-546 (2017)

[83] Sharma A K, Katiyar J K, Bhaumik S, Roy S. Influence of alumina/MWCNT hybrid nanoparticle additives on tribological properties of lubricants in turning operations. Friction 7(2): 153-168 (2018)

[84] Wu J, Huang X Z, Berglund K, Lu X H, Feng X, Larsson R, Shi Y J. CuO nanosheets produced in graphene oxide solution: An excellent anti-wear additive for self-lubricating polymer composites. Compos Sci Technol 162: 86-92 (2018)

[85] An V, Irtegov Y, Izarra C d. Study of Tribological properties of nanolamellar $\mathrm{WS}_{2}$ and $\mathrm{MoS}_{2}$ as additives to lubricants. J Nanomater 2014: 865839 (2014)

[86] Yi M R, Zhang C H. The synthesis of $\mathrm{MoS}_{2}$ particles with different morphologies for tribological applications. Tribol Int 116: 285-294 (2017)

[87] Hu K H, Hu X G, Xu Y F, Huang F, Liu J S. The Effect of morphology on the tribological properties of $\mathrm{MoS}_{2}$ in liquid paraffin. Tribol Lett 40(1): 155-165 (2010) 
[88] Chen Z, Liu X W, Liu Y H, Gunsel S, Luo J B. Ultrathin $\mathrm{MoS}_{2}$ nanosheets with superior extreme pressure property as boundary lubricants. Sci Rep 5: 12869 (2015)

[89] Yang H M, Li J S, Zeng X Q. Tribological behavior of nanocarbon materials with different dimensions in aqueous systems. Friction 8(1): 29-46 (2020)

[90] Tu Z Q, Hu E Z, Wang B B, David K D, Seeger P, Moneke M, Stengler R, Hu K H, Hu X G. Tribological behaviors of Ni-modified citric acid carbon quantum dot particles as a green additive in polyethylene glycol. Friction 8(1): 182-197 (2019)

[91] Kim H S, Park J W, Park S M, Lee J S, Lee Y Z. Tribological characteristics of paraffin liquid with nanodiamond based on the scuffing life and wear amount. Wear 301(1-2): 763-767 (2013)

[92] Joly-Pottuz L, Vacher B, Ohmae N, Martin J M, Epicier $\mathrm{T}$. Anti-wear and friction reducing mechanisms of carbon nano-onions as lubricant additives. Tribol Lett 30(1): 69-80 (2008)

[93] Liu L N, Fang Z P, Gu A J, Guo Z H. Lubrication effect of the paraffin oil filled with functionalized multiwalled carbon nanotubes for bismaleimide resin. Tribol Lett 42(1): 59-65 (2011)

[94] Zhang L L, Pu J B, Wang L P, Xue Q J. Frictional dependence of graphene and carbon nanotube in diamond-like carbon/ionic liquids hybrid films in vacuum. Carbon 80: 734-745 (2014)

[95] Berman D, Erdemir A, Sumant A V. Few layer graphene to reduce wear and friction on sliding steel surfaces. Carbon 54: 454-459 (2013)

[96] Chen G Y, Zhao J, Chen K, Liu S Y, Zhang M Y, He Y Y, Luo J B. Ultrastable lubricating properties of robust self-repairing tribofilms enabled by in situ-assembled polydopamine nanoparticles. Langmuir 36(4): 852-861 (2020)

[97] Washizu H, Kajita S, Tohyama M, Ohmori T, Nishino N, Teranishi H, Suzuki A. Mechanism of ultra low friction of multilayer graphene studied by coarse-grained molecular simulation. Faraday Discuss 156: 279-291, 293-309 (2012)

[98] Berman D, Deshmukh S A, Sankaranarayanan S K R S, Erdemir A, Sumant A V. Extraordinary macroscale wear resistance of one atom thick graphene layer. Adv Funct Mater 24(42): 6640-6646 (2014)

[99] Liu L C, Zhou M, Jin L, Li L C, Mo Y T, Su G S, Li X, Zhu $\mathrm{H} \mathrm{W}$, Tian Y. Recent advances in friction and lubrication of graphene and other 2D materials: Mechanisms and applications. Friction 7(3): 199-216 (2019)

[100] Feng X F, Kwon S, Park J Y, Salmeron M. Superlubric sliding of graphene nanoflakes on graphene. ACS
Nano 7(2): 1718-1724 (2013)

[101] Eswaraiah V, Sankaranarayanan V, Ramaprabhu S. Graphene-based engine oil nanofluids for tribological applications. ACS Appl Mater Interfaces 3(11): 4221-4227 (2011)

[102] Mungse H P, Khatri O P. Chemically functionalized reduced graphene oxide as a novel material for reduction of friction and wear. J Phys Chem 118(26): 14394-14402 (2014)

[103] Schlüter B, Mülhaupt R, Kailer A. Synthesis and tribological characterization of stable dispersions of thermally reduced graphite oxide. Tribol Lett 53(1): 353-363 (2013)

[104] Zhao J, Li Y R, Wang Y F, Mao J Y, He Y Y, Luo J B. Mild thermal reduction of graphene oxide as a lubrication additive for friction and wear reduction. RSC Adv 7(3): 1766-1770 (2017)

[105] Zhao J, Li Y R, Mao J Y, He Y Y, Luo J B. Synthesis of thermally reduced graphite oxide in sulfuric acid and its application as an efficient lubrication additive. Tribol Int 116: 303-309 (2017)

[106] Li X F, Peng S X. Tribology of poly(vinyl alcohol)-carbon nanotube composites. In Proceedings of 2011 International Conference on Electronic \& Mechanical Engineering and Information Technology, Harbin, China, 2011: 1431-1434.

[107] Yu B, Liu Z L, Zhou F, Liu W M, Liang Y M. A novel lubricant additive based on carbon nanotubes for ionic liquids. Mater Lett 62(17-18): 2967-2969 (2008)

[108] Sarker D. Pharmaceutical emulsions: a drug developer's toolbag. Chichester (UK): John Wiley \& Sons, Ltd, 2013

[109] Choi Y, Hwang Y, Park M, Lee J, Choi C, Jung M, Oh $\mathrm{J}$, Lee $\mathrm{J}$ E. Investigation of anti-wear and extreme pressure properties of nano-lubricant using graphite and Ag nanoparticles. J Nanosci Nanotechnol 11(1): 560-565 (2011)

[110] Choi C, Yoo H S, Oh J M. Preparation and heat transfer properties of nanoparticle-in-transformer oil dispersions as advanced energy-efficient coolants. Curr Appl Phys 8(6): 710-712 (2008)

[111] Xing M B, Wang R X. Nanorefrigeration oil formed by $\mathrm{C} 60, \mathrm{CNTs}$ and mineral oil for air conditioner. $A d v$ Mater Res 629: 247-254 (2012)

[112] Kotia A, Ghosh S K. Experimental analysis for rheological properties of aluminium oxide $\left(\mathrm{Al}_{2} \mathrm{O}_{3}\right)$ /gear oil (SAE EP-90) nanolubricant used in HEMM. Ind Lubr Tribol 67(6): 600-605 (2015)

[113] Zhu H T, Li C J, Wu D X, Zhang C Y, Yin Y S. Preparation, characterization, viscosity and thermal conductivity of $\mathrm{CaCO}_{3}$ aqueous nanofluids. Sci China Technol Sci 53(2): 360-368 (2010) 
[114] Mosleh M, Atnafu N D, Belk J H, Nobles O M. Modification of sheet metal forming fluids with dispersed nanoparticles for improved lubrication. Wear 267(5-8): 1220-1225 (2009)

[115] Sharif M Z, Azmi W H, Redhwan A A M, Mamat R, Yusof T M. Performance analysis of $\mathrm{SiO}_{2} / \mathrm{PAG}$ nanolubricant in automotive air conditioning system. Int $J$ Refriger 75: 204-216 (2017)

[116] Ettefaghi E-o-1, Ahmadi H, Rashidi A, Mohtasebi S, Alaei M. Experimental evaluation of engine oil properties containing copper oxide nanoparticles as a nanoadditive. Int J Ind Chem 4(1): 28-33 (2013)

[117] Alazemi A A, Dysart A D, Phuah X L, Pol V G, Sadeghi F. $\mathrm{MoS}_{2}$ nanolayer coated carbon spheres as an oil additive for enhanced tribological performance. Carbon 110: 367-377 (2016)

[118] Wu X H, Gong K L, Zhao G Q, Lou W J, Wang X B, Liu W $\mathrm{M}$. $\quad \mathrm{MoS}_{2} / \mathrm{WS}_{2}$ quantum dots as high-performance lubricant additive in polyalkylene glycol for steel/steel contact at elevated temperature. Adv Mater Interfaces 5(1): 1700859 (2017)

[119] Jatti V S, Singh T P. Copper oxide nano-particles as friction-reduction and anti-wear additives in lubricating oil. J Mech Sci Technol 29(2): 793-798 (2015)

[120] Wan Q M, Jin Y, Sun P C, Ding Y L. Tribological behaviour of a lubricant oil containing boron nitride nanoparticles. Procedia Eng 102: 1038-1045 (2015)

[121] Fontes D H, Ribatski G, Bandarra Filho E P. Experimental evaluation of thermal conductivity, viscosity and breakdown voltage AC of nanofluids of carbon nanotubes and diamond in transformer oil. Diam Relat Mater 58: 115-121 (2015)

[122] Fedele L, Colla L, Bobbo S, Barison S, Agresti F. Experimental stability analysis of different waterbased nanofluids. Nanoscale Res Lett 6(1): 300 (2011)

[123] Kole M, Dey T K. Effect of aggregation on the viscosity of copper oxide-gear oil nanofluids. Int $J$ Therm Sci 50(9): 1741-1747 (2011)

[124] Zheng D, Cai Z B, Shen M X, Li Z Y, Zhu M H. Investigation of the tribology behaviour of the graphene nanosheets as oil additives on textured alloy cast iron surface. Appl Surf Sci 387: 66-75 (2016)

[125] Lou J F, Zhang H, Wang R X. Experimental investigation of graphite nanolubricant used in a domestic refrigerator. Adv Mech Eng 7(2) (2015)

[126] Jiang Z Q, Zhang Y J, Yang G B, Yang K P, Zhang S M, Yu L G, Zhang P Y. Tribological properties of oleylamine-modified ultrathin $\mathrm{WS}_{2}$ nanosheets as the additive in polyalpha olefin over a wide temperature range. Tribol Lett 61(3): 24 (2016)

[127] Kumara C, Luo H, Leonard D N, Meyer H M, Qu J.
Organic-modified silver nanoparticles as lubricant additives. ACS Appl Mater Interfaces 9(42): 37227-37237 (2017)

[128] Peng D X, Chen C H, Kang Y, Chang Y P, Chang S Y. Size effects of $\mathrm{SiO}_{2}$ nanoparticles as oil additives on tribology of lubricant. Ind Lubr Tribol 62(2): 111-120 (2010)

[129] Wang Z Q, Ren R R, Song H J, Jia X H. Improved tribological properties of the synthesized copper/carbon nanotube nanocomposites for rapeseed oil-based additives. Appl Surf Sci 428: 630-639 (2018)

[130] Wu X H, Gong K L, Zhao G Q, Lou W J, Wang X B, Liu W M. Surface modification of $\mathrm{MoS}_{2}$ nanosheets as effective lubricant additives for reducing friction and wear in poly- $\alpha$-olefin. Ind Eng Chem Res 57(23): 8105-8114 (2018)

[131] Dou X, Koltonow A R, He X, Jang H D, Wang Q, Chung Y W, Huang J. Self-dispersed crumpled graphene balls in oil for friction and wear reduction. Proc Natl Acad Sci USA 113(6): 1528-1533 (2016)

[132] Li Y R, Zhao J, Tang C, He Y Y, Wang Y F, Chen J, Mao J Y, Zhou Q Q, Wang B Y, Wei F, Luo J B, Shi G Q. Highly exfoliated reduced graphite oxide powders as efficient lubricant oil additives. $A d v$ Mater Interfaces 3(22): 1600700 (2016)

[133] Zhao J, Huang Y Y, Li Y R, Gao T, Dou Z, Mao J Y, Wang $\mathrm{H}$ D, He Y Y, Li S X, Luo J B. Superhigh-exfoliation graphene with a unique two-dimensional (2D) microstructure for lubrication application. Appl Surf Sci 513: 145608 (2020)

[134] Bai G Y, Wang J Q, Yang Z G, Wang H G, Wang Z F, Yang S R. Preparation of a highly effective lubricating oil additive-Ceria/graphene composite. RSC $A d v$. 4(87): 47096-47105 (2014)

[135] Ren B J, Gao L, Xie B T, Li M J, Zhang S D, Zu g Q, Ran X. Tribological properties and anti-wear mechanism of $\mathrm{ZnO} @$ graphene core-shell nanoparticles as lubricant additives. Tribol Int 144: 106114 (2020)

[136] Zheng D, Wu Y P, Li Z Y, Cai Z B. Tribological properties of $\mathrm{WS}_{2} /$ graphene nanocomposites as lubricating oil additives. RSC Adv 7(23): 14060-14068 (2017)

[137] Clark M D, Subramanian S, Krishnamoorti R. Understanding surfactant aided aqueous dispersion of multi-walled carbon nanotubes. J Colloid Interface Sci 354(1): 144-151 (2011)

[138] Yu W, Xie H Q. A review on nanofluids: Preparation, stability mechanisms, and applications. J Nanomater 2012: 435873 (2012)

[139] Ali M K A, Xianjun H, Elagouz A, Essa F A, 
Abdelkareem M A A. Minimizing of the boundary friction coefficient in automotive engines using A12O3 and $\mathrm{TiO}_{2}$ nanoparticles. J Nanopart Res 18(12): 377 (2016)

[140] Ali M K A, Xianjun H, Mai L, Bicheng C, Turkson R F, Qingping C. Reducing frictional power losses and improving the scuffing resistance in automotive engines using hybrid nanomaterials as nano-lubricant additives. Wear 364-365: 270-281 (2016)

[141] Huang H D, Tu J P, Gan L P, Li C Z. An investigation on tribological properties of graphite nanosheets as oil additive. Wear 261(2): 140-144 (2006)

[142] Xiong X J, Zhang S M, Kang Y K, Yu L G, Yang G B, Zhang P Y. Preparation and evaluation of tribological properties of $\mathrm{cu}$ nanoparticles surface modified by tetradecyl hydroxamic Acid. Tribol Lett 46: 211-220 (2012)

[143] Chen C S, Chen X H, Xu L S, Yang Z, Li W H. Modification of multi-walled carbon nanotubes with fatty acid and their tribological properties as lubricant additive. Carbon 43(8): 1660-1666 (2005)

[144] Bourlinos A B, Gournis D, Petridis D, Szabo T s, Szeri A, De'ka'ny I. Graphite oxide: chemical reduction to graphite and surface modification with primary aliphatic amines and amino acids. Langmuir 19: 6050-6055 (2003)

[145] Wang G X, Shen X P, Wang B, Yao J, Park J. Synthesis and characterisation of hydrophilic and organophilic graphene nanosheets. Carbon 47(5): 1359-1364 (2009)

[146] Zhang W, Zhou M, Zhu H W, Tian Y, Wang K L, Wei J Q, Ji F, Li X, Li Z, Zhang P, Wu D H. Tribological properties of oleic acid-modified graphene as lubricant oil additives. J Phys D Appl Phys 44(20): 205303 (2011)

[147] Han J S, Choi J Y, Yoo M, Lee C S. Synthesis, Dispersion, and tribological performance of alkyl-functionalized graphene oxide as an oil lubricant additive and synergistic interaction with IF-WS 2 . Bull Korean Chem Soc 41(5): 518-529 (2020)

[148] Zhang S H, Qiao Y J, Liu Y H, Ma L R, Luo J B. Molecular behaviors in thin film lubrication-Part one: Film formation for different polarities of molecules. Friction 7(4): 372-387 (2019)

[149] Desanker M, Johnson B, Seyam A M, Chung Y W, Bazzi H S, Delferro M, Marks $\mathrm{T}$ J, Wang Q J. Oil-soluble silver-organic molecule for in situ deposition of lubricious metallic silver at high temperatures. ACS Appl Mater Interfaces 8(21): 13637-13645 (2016)

[150] Zhang B S, Xu B S, Xu Y, Gao F, Shi P J, Wu Y X. Cu nanoparticles effect on the tribological properties of hydrosilicate powders as lubricant additive for steel-steel contacts. Tribol Int 44(7-8): 878-886 (2011)

[151] Chen Y F, Zhang Y J, Zhang S M, Yu L G, Zhang P Y, Zhang $Z$ J. Preparation of nickel-based nanolubricants via a facile in situ one-step route and investigation of their tribological properties. Tribol Lett 51(1): 73-83 (2013)

[152] Alves S M, Barros B S, Trajano M F, Ribeiro K S B, Moura E. Tribological behavior of vegetable oil-based lubricants with nanoparticles of oxides in boundary lubrication conditions. Tribol Int 65: 28-36 (2013)

[153] Wu Y Y, Tsui W C, Liu T C. Experimental analysis of tribological properties of lubricating oils with nanoparticle additives. Wear 262(7-8): 819-825 (2007)

[154] Ran X, Yu X Y, Zou Q. Effect of Particle concentration on tribological properties of zno nanofluids. Tribol Trans 60(1): 154-158 (2016)

[155] Ingole S, Charanpahari A, Kakade A, Umare S S, Menghani J. Tribological behavior of nano $\mathrm{TiO}_{2}$ as an additive in base oil. Wear 301(1-2): 776-785 (2013)

[156] Krishna Sabareesh R, Gobinath N, Sajith V, Das S, Sobhan C B. Application of $\mathrm{TiO}_{2}$ nanoparticles as a lubricant-additive for vapor compression refrigeration systems-An experimental investigation. Int $J$ Refriger 35 (7): 1989-1996 (2012)

[157] Wu H, Zhao J W, Xia W Z, Cheng X W, He A S, Yun J H, Wang L Z, Huang H, Jiao S H, Huang L, Zhang S Q, Jiang Z Y. A study of the tribological behaviour of $\mathrm{TiO}_{2}$ nano-additive water-based lubricants. Tribol Int 109: 398-408 (2017)

[158] Koshy C P, Rajendrakumar P K, Thottackkad M V. Evaluation of the tribological and thermo-physical properties of coconut oil added with $\mathrm{MoS}_{2}$ nanoparticles at elevated temperatures. Wear 330-331: 288-308 (2015)

[159] Srinivas V, Thakur R N, Jain A K. Antiwear, antifriction, and extreme pressure properties of motor bike engine oil dispersed with molybdenum disulfide nanoparticles. Tribol Trans 60(1): 12-19 (2016)

[160] Rapoport L, Lvovsky M, Lapsker I, Leshchinsky V, Volovik Y, Feldman Y, Margolin A, Rosentsveig R, Tenne R. Slow release of fullerene-like $\mathrm{WS}_{2}$ nanoparticles from $\mathrm{Fe}-\mathrm{Ni}$ graphite matrix: A self-lubricating nanocomposite. Nano Lett 1(3): 137-140 (2001)

[161] Ratoi M, Niste V B, Zekonyte J. $\mathrm{WS}_{2}$ nanoparticles-potential replacement for ZDDP and friction modifier additives. $R S C A d v$ 4(41): 21238 (2014)

[162] Chen B S, Gu K C, Fang J H, Wu J, Wang J, Zhang N. 
Tribological characteristics of monodispersed cerium borate nanospheres in biodegradable rapeseed oil lubricant. Appl Surf Sci 353: 326-332 (2015)

[163] Fan X Q, Wang L P. High-performance lubricant additives based on modified graphene oxide by ionic liquids. J Colloid Interface Sci 452: 98-108 (2015)

[164] Zhao J, Mao J Y, Li Y R, He Y Y, Luo J B. Friction-induced nano-structural evolution of graphene as a lubrication additive. Appl Surf Sci 434: 21-27 (2018)

[165] Jiao D, Zheng S H, Wang Y Z, Guan R F, Cao B Q. The tribology properties of alumina/silica composite nanoparticles as lubricant additives. Appl Surf Sci 257(13): 5720-5725 (2011)

[166] Meng Y, Su F Hu, Chen Y Z. Au/Graphene Oxide Nanocomposite Synthesized in Supercritical $\mathrm{CO}_{2}$ Fluid as Energy Efficient Lubricant Additive. ACS Appl Mater Interfaces 9(45): 39549-39559 (2017)

[167] Song W, Yan J C, Ji H B. Tribological study of the SOCNTs@MoS $\mathrm{Momposite}_{2}$ as a lubricant additive: Synergistic effect. Ind Eng Chem Res 57(20): 6878-6887 (2018)

[168] Wang J H, Lu B, Zhang L X, Li T, Yan T T, Li M X. An investigation on the tribological properties of $\mathrm{Co}\left(\mathrm{ReO}_{4}\right)_{2} / \mathrm{MoS}_{2}$ composite as potential lubricating additive at various temperatures. Mater Res Express 5(2): 026522 (2018)

[169] Ratoi M, Niste V B, Walker J, Zekonyte J. Mechanism of action of $\mathrm{WS}_{2}$ lubricant nanoadditives in high-pressure contacts. Tribol Lett 52(1): 81-91 (2013)

[170] Sia S Y, Bassyony E Z, Sarhan A A D. Development of $\mathrm{SiO}_{2}$ nanolubrication system to be used in sliding bearings. Int $J$ Adv Manuf Technol 71(5-8): 1277-1284 (2014)

[171] Rai Y, Neville A, Morina A. Transient processes of $\mathrm{MoS}_{2}$ tribofilm formation under boundary lubrication. Lubricat Sci 28 (7): 449-471 (2016)

[172] Sui T Y, Song B Y, Zhang F, Yang Q X. Effect of particle size and ligand on the tribological properties of amino functionalized hairy silica nanoparticles as an additive to polyalphaolefin. J Nanomater 2015: 492401 (2015)

[173] Bao Y Y, Sun J L, Kong L H. Tribological properties and lubricating mechanism of $\mathrm{SiO}_{2}$ nanoparticles in water-based fluid. IOP Conf Ser Mater Sci Eng 182:
012025 (2017)

[174] Li R Y, Wang Y F, Zhang J Y, Zhang J Y. Origin of higher graphitization under higher humidity on the frictional surface of self-mated hydrogenated carbon films. Appl Surf Sci 494: 452-457 (2019)

[175] Wang Y F, Gao K X, Zhang B, Wang Q, Zhang J Y. Structure effects of $\mathrm{sp}^{2}$-rich carbon films under super-low friction contact. Carbon 137: 49-56 (2018)

[176] Zhao J, He Y Y, Wang Y F, Wang W, Yan L, Luo J B. An investigation on the tribological properties of multilayer graphene and $\mathrm{MoS}_{2}$ nanosheets as additives used in hydraulic applications. Tribol Int 97: 14-20 (2016)

[177] Kalin M, Kogovšek J, Remškar M. Nanoparticles as novel lubricating additives in a green, physically based lubrication technology for DLC coatings. Wear 303(1-2): 480-485 (2013)

[178] Kogovšek J, Remškar M, Kalin M. Lubrication of DLC-coated surfaces with $\mathrm{MoS}_{2}$ nanotubes in all lubrication regimes: Surface roughness and running-in effects. Wear 303(1-2): 361-370 (2013)

[179] Shi S C, Wu J Y, Huang T F, Peng Y Q. Improving the tribological performance of biopolymer coating with $\mathrm{MoS}_{2}$ additive. Surf Coat Technol 303: 250-255 (2016)

[180] Zhang Y, Tang H, Ji X R, Li C S, Chen L, Zhang D, Yang X F, Zhang H T. Synthesis of reduced graphene oxide $/ \mathrm{Cu}$ nanoparticle composites and their tribological properties. RSC Adv 3(48): 26086 (2013)

[181] Çelik O N, Ay N, Göncü Y. Effect of nano hexagonal boron nitride lubricant additives on the friction and wear properties of AISI 4140 steel. Partic Sci Technol 31(5): 501-506 (2013)

[182] Gulzar M, Masjuki H, Kalam M, Varman M, Zulkifli N, Mufti R A, Zahid R, Yunus R. Dispersion stability and tribological characteristics of $\mathrm{TiO}_{2} / \mathrm{SiO}_{2}$ nanocomposites enriched bio-based lubricant. Tribol Trans 60(4): 670-680 (2017)

[183] Choi Y, Lee C, Hwang Y, Park M, Lee J, Choi C, Jung M. Tribological behavior of copper nanoparticles as additives in oil. Curr Appl Phys 9(2S): e124-e127 (2009)

[184] Chu H Y, Hsu W C, Lin J F. Scuffing mechanism during oil-lubricated block-on-ring test with diamond nanoparticles as oil additive. Wear 268(11-12): 1423-1433 (2010) 


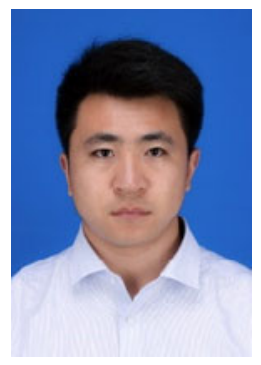

Jun Zhao. He is an associate professor in the College of Mechanical and Electrical Engineering, Beijing University of Chemical Technology, China. He received his Ph.D. degree in Mechanical Engineering

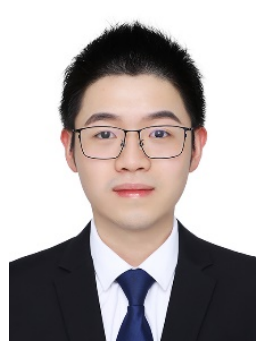

Yiyao HUANG. He received his bachelor degree in 2018 from Dalian University of Technology, Dalian, China. After then, he became a master student at the College

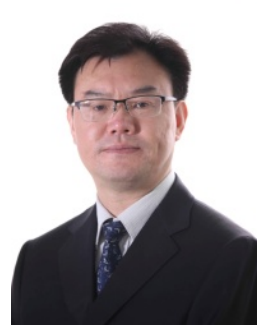

Yongyong He. He received his M.S. and Ph.D. degrees in Mechanical Engineering from Southeast University, Nanjing, China, in 1994 and 1997 respectively. He joined

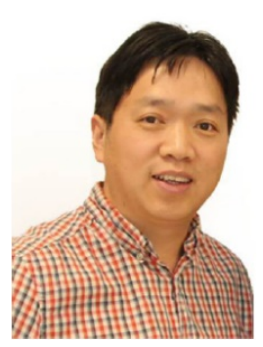

Yijun SHI is now an associate professor in the Division of Machine Elements, Luleå University of Technology, Sweden. He from Tsinghua University, China. His research interests are friction and wear, synthesis of advanced lubricating nanomaterials, and applications of antifriction and antiwear materials.

of Mechanical and Electrical Engineering, Beijing University of Chemical Technology, Beijing, China. His research interests include graphene nanocomposite and other nano lubricant additives.

the State Key Laboratory of Tribology at Tsinghua University in 1999. His current position is a professor and doctoral supervisor. His research areas cover lubrication, material surface modification, and chemical mechanical polishing (CMP).

received his Ph.D. from Nanjing Tech University, China in 2007. His current research interests are tribology and triboelectric nanogenerator. 